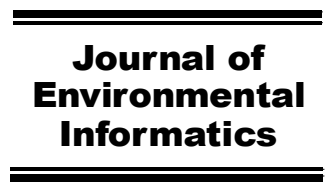

www.iseis.org/jei

\title{
An Integrated Risk Analysis Method for Planning Water Resource Systems to Support Sustainable Development of An Arid Region
}

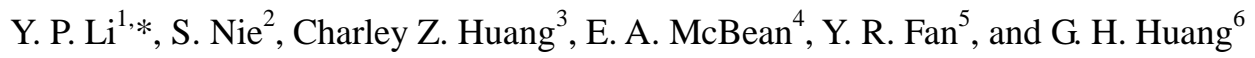 \\ ${ }^{1}$ State Key Laboratory of Water Environment, School of Environment, Beijing Normal University, Beijing 100875, China \\ ${ }^{2}$ Faculty of Applied Science and Engineering, University of Toronto, Toronto, ON M5S 1A4, Canada \\ ${ }^{3}$ Department of Civil Engineering, University of British Columbia, Vancouver, BC, Canada V6T 1Z4 \\ ${ }^{4}$ School of Engineering, University of Guelph, Guelph, ON N1G 2W1, Canada \\ ${ }_{5}^{5}$ Institute for Energy, Environment and Sustainable Communities, University of Regina, Regina, SK S4S 0A2, Canada \\ ${ }^{6} \mathrm{MOE}$ Key Laboratory of Resources and Environmental Systems Optimization, UR-NCEPU, North China Electric Power University, \\ Beijing 102206, China
}

Received 18 May 2016; revised 8 January 2017; accepted 13 February 2017; published online 25 March 2017

\begin{abstract}
An interval-based two-stage risk analysis (ITRA) method is developed for planning water resource systems associated with uncertainties presented in terms of probability distributions and interval values. Risk measures are employed to assess the impacts of degrees of the preference of decision makers on the tradeoff between system benefits and expected economic losses. ITRA is applied to a case study of the Kaidu-kongque watershed located in an arid region of northwestern China. A series of scenarios are examined based on different risk measures, results of which reflect decision makers' attitudes toward risk aversion and options for water-resource allocation under system-reliability levels. Results disclose that both uncertainties of system components and risk attitudes of decision makers have significant effects on water-allocation patterns and economic benefits. Model outputs link the pre-regulated water-allocation targets in decision making with various scales of regionalization policies (due to existence of uncertainties of meeting target flows). Results reveal that the competitiveness can exacerbate the ecological water shortage when limited water resources are available for multiple users in the arid region. The methodology and findings can help managers to gain scientific understanding of the consequences of water allocation decisions when planning in a fast-growing economic development and extremely arid region.
\end{abstract}

Keywords: conditional value-at-risk, decision making, optimization, stochastic programming, water resource systems, uncertainty

\section{Introduction}

Sustainable development has been widely recognized as an effective means for harmonizing human society and natural systems under multiple pressures of economic prosperity, ecoenvironmental protection, and human health. Water is considered the bloodstream of the biosphere, but its management is one of the most important challenges for human development. These reflect some important concepts of sustainability in water resources planning, such as demand management, supply reliability and flexibility, negative impact control, technology adaptation, financial feasibility, and economic efficiency (Cai et al., 2002; Li et al., 2011). Currently, population growth, socioeconomic development, and climate change are exerting ever-increasing pressure on water resource systems (particularly in arid and semi-arid regions), forcing managers and stakeholders to make decisions regarding water allocation with a more sustainable ecological and environmental manner (Wang

\footnotetext{
${ }^{*}$ Corresponding author. Tel.: +86 106177 3887; fax: +86 1061773889.

E-mail address: yongping.li@iseis.org (Y. P. Li).
}

SSN: 1726-2135 print/1684-8799 online

(C) 2017 ISEIS All rights reserved. doi: 10.3808/jei.201700359 et al., 2011, 2012; Shafiee-Jood et al., 2014; Rahmani and Zarghami, 2015). In watershed systems, effective planning of allocation of water resources is fundamental for facilitating socio-economic development and eco-environmental sustainability. Nevertheless, achieving a desired water-resource allocation management strategy is difficult since social and institutional systems as well as the economics of water use are interconnected, and continuously varying, while many conflicting factors have to be balanced due to the complexities of realworld problems (Li et al., 2009). For example, available water resources are influenced by stochastic events such as temperature and precipitation, which are not measured with certainty but in fact represented as a probability distribution around the actual streamflow. The effects of inaccuracies in estimating the streamflow can further extend into water allocation, system assessment, as well as management strategy (Nazemi and Wheater, 2014; Ahmadi et al., 2015; Fan et al., 2016). All of these imply that risk management for water resource systems that are associated with various uncertainties is desired.

Consequently, a number of researchers have employed stochastic programming for planning and managing water resource systems where coefficients (input data) are not certainly known but can be represented in probabilistic forms, and where economic targets are designed as indicators to examine efficient 
water-allocation strategies (Harrison, 2007; Wang et al., 2010; Housh et al., 2013; Li et al., 2015; Fan et al., 2015). Two-stage stochastic programming (TSP) is useful for problems where an analysis of policy scenarios is desired and the related data are random in nature. In TSP, a decision is first made before values of random variables are disclosed; then, after the random events have occurred and their values are revealed, a secondstage decision can be made in order to minimize penalties that may appear due to any infeasibility (Birge and Louveaux 1997; Li et al., 2014; Nematian, 2016). Nevertheless, the objective of TSP model is to minimize the sum of the first- and secondstage costs, without considering risk control issues that need decision makers' implicit knowledge. The TSP model would be likely to achieve high system benefit under an advantageous condition, which may also generate high penalties (high economic losses) when the pre-regulated target cannot be satisfied under a disadvantageous condition.

Conditional value-at-risk (CVaR) is a risk measurement strategy based on probability distributions of random variables, which is modified from the value-at-risk (VaR). Compared to VaR-based models, CVaR-based models are less computationally demanding due to the fact that modeling CVaR only requires linear constraints and continuous variables (Huang et al., 2014). In the past decades, the CVaR-based models were successfully employed for planning financial, production, energy and water-resource systems (Brandtner, 2013; Soleimani and Govindan, 2014; Marrero et al., 2015). Piantadosi et al. (2008) coupled stochastic dynamic programming with conditional value-at-risk (CVaR) criteria for managing storm water, where an optimal pumping policy for a connected storage-dams system associated with a penalty for increased risk of environmental damage was identified. Khor et al. (2014) addressed the problem of integrated water network synthesis under uncertainty with risk management, with a major contribution of this research work being to propose a stepwise solution strategy to reduce the computational load for a large number of scenarios. Generally, CVaR-based stochastic programming is capable of handling probabilistic uncertainties which are often related to resource availability as well as taking into the account the average loss exceeding the VaR.

This study aims to advance an interval-based two-stage risk analysis (ITRA) approach for supporting water resource systems planning and management, where uncertainties expressed as probabilities and intervals can be tackled. ITRA is applied to planning allocation of water resources for the Kaidukongque watershed (located in the middle reaches of the Tarim River Basin), which is located in an extremely arid region. This watershed is also one of the most important cotton and grain bases in northwestern China. Scenarios corresponding to different risk levels will be examined, which can help generate decision alternatives with varied tradeoffs between system optimality and reliability. A comparison with the conventional TSP approach is described to demonstrate that ITRA by considering the effects of the variability of random outcomes (i.e. the random total costs) provides more robust solutions.

\section{Methodology}

When uncertainties are expressed as probability distributions, while decisions need to be made periodically over time, the study problem can be formulated as a TSP with recourse. In TSP, decision makers are required to assign a cost to recourse activities that are taken to ensure feasibility of the second-stage problem. Thus, we have:

$\operatorname{Max} f=\sum_{j=1}^{n_{1}} c_{j} x_{j}-\sum_{j=1}^{n_{2}} \sum_{h=1}^{s} p_{h} d_{j} y_{j h}$

subject to:

$\sum_{j=1}^{n_{1}} a_{r j} x_{j} \leq b_{r}, \quad r=1,2, \cdots, m_{1}$

$\sum_{j=1}^{n_{1}} a_{i j} x_{j}+\sum_{j=1}^{n_{2}} a_{i j}^{\prime} y_{j h} \geq \tilde{w}_{h}, i=1,2, \cdots, m_{2} ; h=1,2, \cdots, s$

$x_{j} \geq 0, j=1,2, \cdots, n_{1}$

$y_{j h} \geq 0, j=1,2, \cdots, n_{2} ; \forall h$

where $x_{j}$ represent the first-stage decision variables, which have to be decided before the actual realizations of the random variables; $y_{j h}$ denote the second-stage decision variables, which are related to the recourse actions against any infeasibilities arising due to particular realizations of the uncertainties; $w_{h}$ are random variables with probability levels $p_{h}(h=1,2, \ldots, \mathrm{s})$ and $\sum p_{h}=1$.

From model (1, a through e), optimal solutions leading to a maximum system benefit can be obtained due to the maximization of economic benefit in the objective function. The possible loss is computed as the expected value of different probability conditions, such that the severity of extreme risks may be somewhat underestimated. The solutions from model $(1 \mathrm{a} \sim \mathrm{e})$ may lead to tremendous losses when an extremely adverse condition occurs. Conditional value-at-risk (CVaR) can be used to examine the risk loss under specific probabilistic distributions (Andersson et al., 2001). The CVaR is defined as the mean loss, given that the loss is greater than or equal to the value-at-risk (VaR), which can be used in the conjunction with $\mathrm{VaR}$ and is applicable to the estimation of risks with non-symmetric return-loss distributions (Rockafellar and Uryasey, 2002; Soleimani and Govindan, 2014).

Let $f(x, y)$ be a loss function depending upon the decision vector $x$ and a random vector $y$ with a probability density function $p(y)$. The probability of $f(x, y)$ not exceeding a threshold value $\eta$ can be defined as:

$\psi(x, \eta)=\int_{f(x, y) \leq \eta} p(y) d y$

Given a confidence level $\alpha \in(0,1)$, the VaR associated with the decision variable $(x)$ can be expressed as: 
$\operatorname{VaR}_{\alpha}(x)=\min \{\eta \in R: \psi(x, \eta) \geq \alpha\}$

The corresponding $C V a R$ is the conditional expectation of the loss of the portfolio (expected value) exceeding or equal to the VaR (Rockafellar and Uryasey, 2002):

$$
\operatorname{CVaR}_{\alpha}(x)=(1-\alpha)^{-1} \int_{f(x, y) \geq \operatorname{VaR}_{\alpha}(x)} f(x, y) p(y) d y
$$

The $C V a R$ is a coherent risk measure and takes into account the extremely large losses that may occur. Then, Equation (4) has an equivalent form as follows:

$\operatorname{CVaR}_{\alpha}(x)=\min _{\eta \in R} F_{\alpha}(x, \eta)$

$F_{\alpha}(x, \eta)=\eta+(1-\alpha)^{-1} E\left[(f(x, y)-\eta]^{+}\right.$

where $E(\cdot)$ denotes the expectation value with respect to $p(y)$ and $[t]^{+}=\max \{t, 0\}$. Assuming random vector $y=\left\{y_{1}, y_{2}, \ldots\right.$, $\left.y_{K}\right\}$, then $F_{\alpha}(x, \eta)$ can be calculated approximately as follows:

$$
F_{\alpha}(x, \eta)=\eta+(1-\alpha)^{-1} \sum_{k=1}^{K} p_{k}\left[f\left(x, y_{k}\right)-\eta\right]^{+}
$$

where $p_{k}$ is the probability of scenario $y_{k}$. Equation (6) can be solved using linear programming. TSP can deal with uncertainties presented as random variables with known probability distributions. In water resource management problems, besides the stochastic nature of streamflow, market participants in deregulated systems face the uncertainties in benefit/cost parameters and allocation targets and they may be too imprecise or not correctly described using stochastic form. Interval-parameter programming (IPP) is an alternative for handling uncertainties in the model's left- and/or right-hand sides as well as those that cannot be quantified as membership or distribution functions (Huang and Loucks, 2000; Li et al., 2010). Introducing the concepts of $C V a R$ and IPP into the TSP framework, an interval-based two-stage risk analysis (ITRA) model can be formulated as:

$$
\operatorname{Max} f^{ \pm}=\sum_{j=1}^{n_{1}} c_{j}^{ \pm} x_{j}^{ \pm}-\sum_{j=1}^{n_{2}} \sum_{h=1}^{s} p_{h} d_{j}^{ \pm} y_{j h}^{ \pm}-\lambda\left[\eta^{ \pm}+(1-\alpha)^{-1} \sum_{h=1}^{s} p_{h} v_{h}^{ \pm}\right]
$$

subject to:

$$
\begin{aligned}
& \sum_{j=1}^{n_{1}} a_{r j}^{ \pm} x_{j}^{ \pm} \leq b_{r}^{ \pm}, \quad r=1,2, \ldots, m_{1} \\
& \sum_{j=1}^{n_{1}} a_{i j}^{ \pm} x_{j}^{ \pm}+\sum_{j=1}^{n_{2}} a^{\prime \pm} y_{j h}^{ \pm} \leq \tilde{w}_{i h}^{ \pm}, \quad i=1,2, \ldots, m_{2} ; h=1,2, \ldots, s
\end{aligned}
$$

$$
v_{h}^{ \pm} \geq \sum_{j=1}^{n_{2}} d_{j}^{ \pm} y_{j h}^{ \pm}-\eta^{ \pm}, \quad \forall h
$$

$$
\begin{aligned}
& x_{j}^{ \pm} \geq 0, j=1,2, \ldots, n_{1} \\
& y_{j h}^{ \pm} \geq 0, \quad j=1,2, \ldots, n_{2} ; \forall h \\
& \eta^{ \pm} \geq 0
\end{aligned}
$$

where '-' and '+' superscripts represent lower and upper bounds of interval parameters/variables, respectively; $\alpha$ is the confidence level; $\lambda$ is a goal programming weight, through varying the $\lambda$ level, decision makers can acquire the compromise between expected system benefit and system-failure risk; $\eta^{ \pm}$is the system's maximum loss under $\alpha$ level; $v_{h}^{ \pm}$is the positive auxiliary variable; and $\lambda\left[\eta^{ \pm}+(1-\alpha)^{-1} \sum_{h=1}^{s} p_{h} v_{h}^{ \pm}\right]$denotes the risk function of CVaR under $\alpha$ level.

A two-step solution method is proposed for solving model (7). The submodel corresponding to $f^{+}$can be formulated in the first step when the system objective is to be maximized; the other submodel (corresponding to $f^{-}$) can then be formulated based on the solution of the first submodel. Let $x_{j}^{ \pm}(j=1,2, \ldots$, $\left.k_{1}\right)$ and $y_{j h}^{ \pm}\left(\mathrm{j}=1,2, \ldots, k_{2}\right)$ be decision variables with positive coefficients in the objective function; $x_{j}^{ \pm}\left(j=k_{1}+1, k_{1}+2, \ldots\right.$, $\left.n_{1}\right)$ and $y_{j h}^{ \pm}\left(j=k_{2}+1, k_{2}+2, \ldots, n_{2}\right)$ are variables with negative coefficients. Thus, we have:

Upper submodel

$$
\begin{aligned}
& \operatorname{Max} f^{+}=\left(\sum_{j=1}^{j_{1}} c_{j}^{+} x_{j}^{+}+\sum_{j=j_{1}+1}^{n_{1}} c_{j}^{+} x_{j}^{-}\right)-\sum_{h=1}^{s} p_{h}\left(\sum_{j=1}^{j_{2}} d_{j}^{-} y_{j h}^{-}+\right. \\
& \left.\sum_{j=j_{2}+1}^{n_{2}} d_{j}^{-} y_{j h}^{+}\right)-\lambda\left[\eta^{-}+(1-\alpha)^{-1} \sum_{h=1}^{s} p_{h} v_{h}^{-}\right]
\end{aligned}
$$

subject to:

$$
\begin{aligned}
& \sum_{j=1}^{j_{1}}\left|a_{r j}\right|^{-} \operatorname{Sign}\left(a_{r j}^{-}\right) x_{j}^{+}+\sum_{j=j_{1}+1}^{n_{1}}\left|a_{r j}\right|^{+} \operatorname{Sign}\left(a_{r j}^{+}\right) x_{j}^{-} \leq b_{r}^{+}, \forall r \\
& \sum_{j=1}^{j_{1}}\left|a_{i j}\right|^{-} \operatorname{Sign}\left(a_{i j}^{-}\right) x_{j}^{+}+\sum_{j=j_{1}+1}^{n_{1}}\left|a_{i j}\right|^{+} \operatorname{Sign}\left(a_{i j t}^{+}\right) x_{j}^{-}+\sum_{j=1}^{j_{2}}\left|a_{i j}^{\prime}\right|^{+} \\
& \operatorname{Sign}\left(a_{i j}^{+}\right) y_{j h}^{-}+\sum_{j=j_{2}+1}^{n_{2}}\left|a_{i j}^{\prime}\right|^{-} \operatorname{Sign}\left(a_{i j}^{\prime-}\right) y_{j h}^{+} \leq \tilde{w}_{i h}^{+}, \forall i, h \\
& v_{h}^{-} \geq\left(\sum_{j=1}^{j_{2}} d_{j}^{-} y_{j h}^{-}+\sum_{j=j_{2}+1}^{n_{2}} d_{j}^{-} y_{j h}^{+}\right)-\eta^{-}, \forall h
\end{aligned}
$$

$x_{j}^{+} \geq 0, j=1,2, \ldots, j_{1}$

$x_{j}^{-} \geq 0, j=j_{1}+1, j_{1}+2, \cdots, n_{1}$

$y_{j h}^{-} \geq 0, \quad \forall h ; j=1,2, \ldots, j_{2}$

$y_{j h}^{+} \geq 0, \quad \forall h ; j=j_{2}+1, j_{2}+2, \cdots, n_{2}$

$\eta^{-} \geq 0$ 
$\underline{\text { Lower submodel }}$

$$
\begin{aligned}
& \operatorname{Max} f^{-}=\left(\sum_{j=1}^{j_{1}} c_{j}^{-} x_{j}^{-}+\sum_{j=j_{1}+1}^{n_{1}} c_{j}^{-} x_{j}^{+}\right)-\sum_{h=1}^{s} p_{h}\left(\sum_{j=1}^{j_{2}} d_{j}^{+} y_{j h}^{+}+\right. \\
& \left.\sum_{j=j_{2}+1}^{n_{2}} d_{j}^{+} y_{j h}^{-}\right)-\lambda\left[\eta^{+}+(1-\alpha)^{-1} \sum_{h=1}^{s} p_{h} v_{h}^{+}\right]
\end{aligned}
$$

subject to:

$$
\begin{aligned}
& \sum_{j=1}^{j_{1}}\left|a_{r j}\right|^{+} \operatorname{Sign}\left(a_{r j}^{+}\right) x_{j}^{-}+\sum_{j=j_{1}+1}^{n_{1}}\left|a_{r j}\right|^{-} \operatorname{Sign}\left(a_{r j}^{-}\right) x_{j}^{+} \leq b_{r}^{-}, \forall r \\
& \sum_{j=1}^{j_{1}}\left|a_{i j}\right|^{+} \operatorname{Sign}\left(a_{i j}^{+}\right) x_{j}^{-}+\sum_{j=j_{1}+1}^{n_{1}}\left|a_{i j}\right|^{-} \operatorname{Sign}\left(a_{i j}^{-}\right) x_{j}^{+}+\sum_{j=1}^{j_{2}}\left|a_{i j}^{\prime}\right|^{-} \\
& \operatorname{Sign}\left(a_{i j}^{\prime-}\right) y_{j h}^{+}+\sum_{j=j_{2}+1}^{n_{2}}\left|a_{i j}^{\prime}\right|^{+} \operatorname{Sign}\left(a_{i j}^{++}\right) y_{j h}^{-} \leq \tilde{w_{i h}}, \forall i, h \\
& v_{h}^{+} \geq\left(\sum_{j=1}^{j_{2}} d_{j}^{+} y_{j h}^{+}+\sum_{j=j_{2}+1}^{n_{2}} d_{j}^{+} y_{j h}^{-}\right)-\eta^{+}, \forall h \\
& 0 \leq x_{j}^{-} \leq x_{j o p t}^{+}, j=1,2, \ldots, j_{1} \\
& x_{j}^{+} \geq x_{j o p t}^{-}, j=j_{1}+1, j_{1}+2, \cdots, n_{1} \\
& y_{j h}^{+} \geq y_{j h o p t}^{-}, j=1,2, \cdots, j_{2} ; \forall h \\
& 0 \leq y_{j h}^{-} \leq y_{j h o p t}^{+}, j=j_{2}+1, j_{2}+2, \cdots, n_{2} ; \forall h \\
& \eta^{+} \geq 0
\end{aligned}
$$

By solving the two submodels, interval solutions (associated with $\alpha$ and $\lambda$ levels) can be obtained. Additional solutions based on the inputs of interval and random values can be obtained by repeating the process via changing $\alpha$ and $\lambda$ levels. Then, the final solutions for the objective-function value and decision variables under various $\alpha$ and $\lambda$ levels can be obtained.

\section{Case Study}

\subsection{Study Area and Problem Identification}

The Kaidu-kongque watershed (abbreviated as Kaikong watershed with an area of $31,400 \mathrm{~km}^{2}$, as shown in Figure 1) is located in the middle reaches of the Tarim River Basin, which is one of the most important bases of cotton and grain in northwestern China. The Tarim River is the longest inland river of China with a length of around $1,300 \mathrm{~km}$, which is formed by the union of Aksu, Hotan, and Yarkant rivers, and flows east along the northern edge of the desert. The Tarim River Basin has an extreme arid desert climate with an average annual temperature of 10.6 to $11.5^{\circ} \mathrm{C}$; its multi-annual mean precipitation is $116.8 \mathrm{~mm}$ while the annual potential evaporation ranges from 2,500 to $3,000 \mathrm{~mm}$; more than $80 \%$ of the total annual precipitation falls between May and October in the high flow season and less than $20 \%$ of the total falls from November to the following April (Chen et al., 2009).

The streamflow in the watershed is mainly initiated from the snowmelt in the Tianshan Mountain; large variations in the annual snow pack in the mountainous areas can further translate into extreme events, most notably droughts in its downstream regions. Climate change has a measurable effect on hydrological cycle, altering the amount, distribution and timing of available water resources (Zhuang et al., 2016). The watershed has been suffering extremely ecological degradation since the 1970 s and nearly one-third reach in the river's downstream has been dried out. The river's lower reach drying up has been accompanied by the disappearance of the terminal lake (Lopnor Lake); the groundwater levels have dropped to $5 \sim 8 \mathrm{~m}$ below the surface, and the threat of soil and groundwater salinization has become more serious. The stability of the ecosystem has decreased with severe eco-environmental problems because of over-exploitation of water and land resources to allow rapid economic development. The local authority is seeking a solid approach to achieve optimal allocation of water resources, which can also serve as a market-based way to support ecological sustainable decision-making against ecosystem desertification.

The Kaidu-kongque River mainly contributes water to municipal, industry, stockbreeding, forestry and agricultural sectors of six cities (named as Kuerle, Yanqi, Hejing, Heshuo, Bohu and Yuli); it is also the water source for ecosystem recovery in the lower reaches of the Tarim River Basin. Water stress in the study area has intensified, resulting in water use conflicts between midstream and downstream areas and also among municipal, agricultural (that is still the largest water consumer) and industrial sectors (that have been growing fast). In fact, the study watershed is an important agricultural producing base in the Xinjiang Uyghur Autonomous Region. Irrigation growth, together with rapid growth of industrial and municipal water usage, has resulted in a dramatic increase of water withdrawals in the midstream. The risk of reduced water supply is negatively impacting the economies and livelihoods of the denselypopulated midstream areas. Due to the minimal precipitation in the oasis, more than $95 \%$ of the arable land requires irrigation. Agricultural irrigation and ecological sustainability occupy more than $75 \%$ of the total water consumption, such that conflict between economic development and ecological protection is becoming increasingly serious.

In recent years, the rapid urbanization, the speedy industrial development, and the shifting of the economic growth of the watershed have boosted the deterioration of the eco-environment as well as the shortage of water resources. Prosperous planting and the breeding industries generate that agricultural product processing and manufacturing play an important role in the local economy, which accelerates the process of agricultural industrialization. The rich mineral and oil resources form an industrial structure dominated by mining, chemical indutry, and fossil oil industry; meanwhile, textiles, electric power, papermaking and transportation are keeping pace with the development of the mainstay industries. When scarce water resources are distributed among multiple competing users, its reple- 


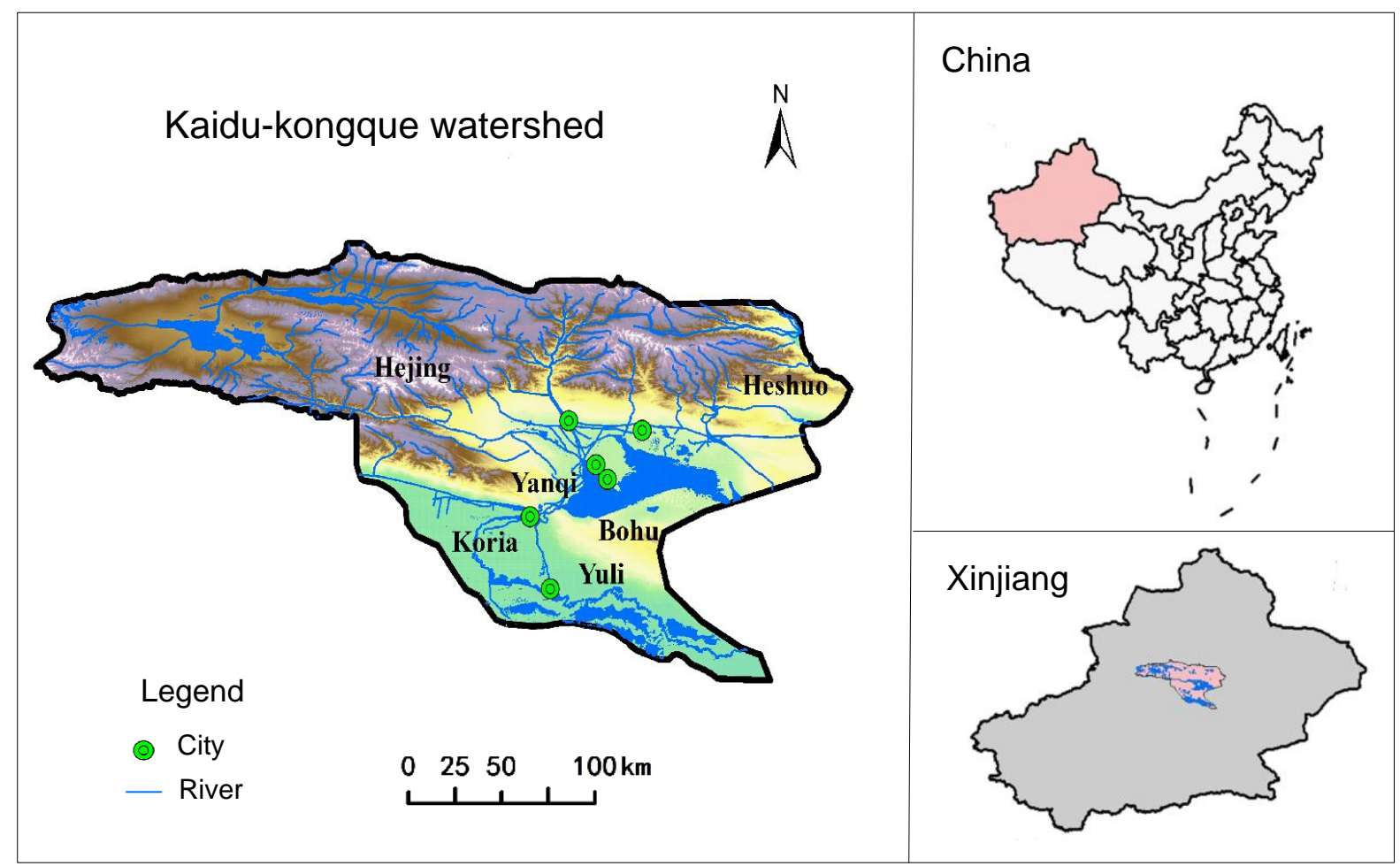

Figure 1. The study area.

nishment as well as satisfying users' demands is subject to considerable uncertainty. Cost/benefit optimization and risk management models can assist the authority in its decisions about striking the balance between the level of target delivery to the users, and the level of risk that this delivery will not be met. Thus, the planning of water resource systems plays a key role in the growth of the regional economy and the stability of oasis ecosystems in such an arid region.

\subsection{Problem Formulation}

The challenge of water resource systems management adhering to the principle of sustainable development is one of the significant concerns to the local decision makers. Given a quantity of water that is promised to each user; if this water is delivered, it will result in net benefit to the local economy; however, if the promised water is not delivered, either the water must be obtained from alternative and more expensive sources or the demand must be curtailed, resulting in penalty (i.e. loss) to the local economy. Based on the ITRA approach, the study problem can be formulated as follows:

$$
\begin{aligned}
& \operatorname{Max} f^{ \pm}=\sum_{i=1}^{6} \sum_{j=1}^{6} N B_{i j}^{ \pm} T_{i j}^{ \pm}-\sum_{i=1}^{6} \sum_{j=1}^{6} \sum_{h=1}^{5} p_{h} C_{i j}^{ \pm} D_{i j h}^{ \pm}-\sum_{i=1}^{6} \sum_{j=1}^{6} \sum_{h=1}^{5} p_{h} \\
& V C_{i j}^{ \pm}\left(T_{i j}^{ \pm}-D_{i j h}^{ \pm}\right)-\lambda\left[\eta^{ \pm}+(1-\alpha)^{-1} \sum_{h=1}^{5} p_{h} v_{h}^{ \pm}\right]
\end{aligned}
$$

subject to:

$$
\sum_{i=1}^{6} \sum_{j=1}^{6}\left(T_{i j}^{ \pm}-D_{i j h}^{ \pm}\right) \leq q_{h}^{ \pm} \quad \forall h
$$

[Water availability constraint]

$T_{i j}^{ \pm}-D_{i j h}^{ \pm} \geq 0 \quad \forall i, j, h$

[Water supply constraint]

$D e_{i j}^{-} \leq T_{i j}^{ \pm} \leq D e_{i j}^{+} \quad \forall i, j$

[Water target constraint]

$\sum_{j=1}^{6} \sum_{h=1}^{5} p_{h}\left(T_{i j}^{ \pm}-D_{i j h}^{ \pm}\right) \geq A G \cdot T_{i j}^{ \pm} \quad i=3$

[Constraint for satisfying agricultural security]

$\sum_{j=1}^{6} \sum_{h=1}^{5} p_{h}\left(T_{i j}^{ \pm}-D_{i j h}^{ \pm}\right) \geq E C \cdot T_{i j}^{ \pm} \quad i=6$

[Constraint for satisfying ecological water demand]

$\sum_{i=1}^{6} \sum_{h=1}^{5} p_{h}\left(T_{i j}^{ \pm}-D_{i j h}^{ \pm}\right) \geq R E \sum_{i=1}^{I} T_{i j}^{ \pm} \quad \forall j$

[Constraint for satisfying regional development]

$v_{h}^{ \pm} \geq \sum_{i=1}^{6} \sum_{j=1}^{6} C_{i j}^{ \pm} D_{i j h}^{ \pm}-\eta^{ \pm} \quad \forall h$

[CVaR constraint] 
Table 1. Economic Data Related to Water Allocation

\begin{tabular}{|c|c|c|c|c|c|c|}
\hline & Municipality & Industry & Agriculture & Stockbreeding & Forestry & Ecology \\
\hline \multicolumn{7}{|c|}{ Net benefit when pre-regulated water is delivered $\left(\mathrm{US} \$ / \mathrm{m}^{3}\right)$} \\
\hline Kuerle & {$[6.03,6.67]$} & {$[4.53,4.67]$} & {$[2.32,2.52]$} & {$[3.90,4.02]$} & {$[1.96,2,12]$} & {$[1.27,1.35]$} \\
\hline Yanqi & {$[5.50,6.04]$} & {$[2.60,2.93]$} & {$[1.42,1.56]$} & {$[3.22,3.35]$} & {$[1.68,1.93]$} & {$[1.35,1.43]$} \\
\hline Hejing & {$[4.67,4.81]$} & {$[3.73,3.81]$} & {$[1.50,1.67]$} & {$[3.50,3.64]$} & {$[1.54,1.78]$} & {$[0.92,0.98]$} \\
\hline Heshuo & {$[5.30,5.53]$} & {$[3.44,3.62]$} & {$[2.01,2.34]$} & {$[3.62,3.87]$} & {$[1.66,1.94]$} & {$[1.08,1.14]$} \\
\hline Bohu & {$[4.91,5.12]$} & {$[3.61,3.74]$} & {$[1.78,2.01]$} & {$[3.15,3.31]$} & {$[1.53,1.85]$} & {$[1.21,1.29]$} \\
\hline Yuli & {$[4.60,5.26]$} & {$[3.22,3.45]$} & {$[2.23,2.46]$} & {$[3.93,4.10]$} & {$[1.69,1.98]$} & {$[1.01,1.06]$} \\
\hline \multicolumn{7}{|c|}{ Penalty when the pre-regulated water is not delivered $\left(\mathrm{US} \$ / \mathrm{m}^{3}\right)$} \\
\hline Kuerle & {$[7.24,8.01]$} & {$[5.44,5.60]$} & {$[2.78,3.01]$} & {$[4.67,4.82]$} & {$[2.35,2.54]$} & {$[1.52,1.62]$} \\
\hline Yanqi & {$[6.60,7.25]$} & {$[3.12,3.52]$} & {$[1.70,1.87]$} & {$[3.85,4.01]$} & {$[2.02,2.32]$} & {$[1.60,1.71]$} \\
\hline Hejing & {$[5.60,5.76]$} & {$[4.48,4.71]$} & {$[1.84,2.23]$} & {$[4.19,4.36]$} & {$[1.85,2.14]$} & {$[1.10,1.17]$} \\
\hline Heshuo & {$[6.36,6.64]$} & {$[4.13,4.34]$} & {$[2.41,2.82]$} & {$[4.33,4.63]$} & {$[1.99,2.33]$} & {$[1.29,1.37]$} \\
\hline Bohu & {$[5.89,6.12]$} & {$[4.35,4.49]$} & {$[2.14,2.40]$} & {$[2.56,2.87]$} & {$[1.84,2.21]$} & {$[1.45,1.55]$} \\
\hline Yuli & {$[5.52,6.31]$} & {$[3.86,4.13]$} & {$[2.68,2.95]$} & {$[4.70,3.53]$} & {$[2.03,2.39]$} & {$[1.21,1.27]$} \\
\hline \multicolumn{7}{|c|}{ Cost for water allocation $\left(\mathrm{US} \$ / \mathrm{m}^{3}\right)$} \\
\hline & {$[1.20,1.31]$} & {$[0.71,0.82]$} & {$[0.53,0.60]$} & {$[0.42,0.51]$} & {$[0.13,0.17]$} & {$[0.11,0.15]$} \\
\hline
\end{tabular}

Table 2. Water Demands from Users (unit: $10^{6} \mathrm{~m}^{3}$ )

\begin{tabular}{lllllll}
\hline & Municipality & Industry & Agriculture & Stockbreeding & Forestry & Ecology \\
\hline Kuerle & {$[14.49,16.10]$} & {$[64.17,71.30]$} & {$[288.77,346.52]$} & {$[21.23,23.40]$} & {$[123.24,135.56]$} & {$[80.73,96.87]$} \\
Yanqi & {$[8.48,9.43]$} & {$[42.16,46.85]$} & {$[173.88,208.41]$} & {$[15.05,16.71]$} & {$[60.02,66.57]$} & {$[48.65,58.87]$} \\
Hejing & {$[4.45,4.95]$} & {$[20.80,23.12]$} & {$[91.08,107.47]$} & {$[8.04,8.92]$} & {$[55.21,61.28]$} & {$[26.91,32.83]$} \\
Heshuo & {$[0.52,0.58]$} & {$[2.33,2.59]$} & {$[10.45,12.56]$} & {$[4.12,4.57]$} & {$[44.67,49.58]$} & {$[3.11,3.65]$} \\
Bohu & {$[4.50,5.05]$} & {$[19.67,21.85]$} & {$[87.98,105.57]$} & {$[9.20,10.21]$} & {$[66.23,73.58]$} & {$[25.88,31.83]$} \\
Yuli & {$[6.21,6.90]$} & {$[27.95,31.05]$} & {$[124.20,149.04]$} & {$[10.87,12.06]$} & {$[58.46,64.89]$} & {$[36.23,45.27]$} \\
\hline
\end{tabular}

Table 3. Available Water for Allocation

\begin{tabular}{llll}
\hline & Probability & River flow $\left(10^{6} \mathrm{~m}^{3}\right)$ & Available water for allocation $\left(10^{6} \mathrm{~m}^{3}\right)$ \\
\hline Low $(\mathrm{L})$ & 0.152 & {$[2459,2901]$} & {$[983.6,1160.4]$} \\
Low-Medium $(\mathrm{LM})$ & 0.478 & {$[2917,3500]$} & {$[1166.8,1400.0]$} \\
Medium (M) & 0.239 & {$[3560,4162]$} & {$[1424.0,1664.8]$} \\
Medium-High $(\mathrm{MH})$ & 0.087 & {$[4185,4856]$} & {$[1674.0,1942.4]$} \\
High $(\mathrm{H})$ & 0.044 & {$[5015,5708]$} & {$[2006.0,2283.2]$} \\
\hline
\end{tabular}

$T_{i j}^{ \pm} \geq 0 \quad \forall i, j$

$D_{i j h}^{ \pm} \geq 0 \quad \forall i, j, h$

$\eta^{ \pm} \geq 0$

$(10 \mathrm{k})$

[Non-negative constraints]

where $i$ denotes water users of municipality, industry, agriculture, stockbreeding, forestry and ecology; $j$ represents the name of the city (i.e. Kuerle, Yanqi, Hejing, Heshuo, Bohu and Yuli); $h$ is available water level; $f^{ \pm}$is expected system benefit (US\$); $C_{i j}^{ \pm}$is the penalty (loss) per unit of water not delivered to user $i$ in city $j\left(\mathrm{US} \$ / \mathrm{m}^{3}\right)$, and $C_{i j}^{ \pm} \geq N B_{i j}^{ \pm} ; D_{i j h}^{ \pm}$is the probabilistic deficit of water that cannot be delivered under level $h\left(\mathrm{~m}^{3}\right)$, which is the recourse decision variable; $N B_{i j}^{ \pm}$denotes the benefit parameter for user $i$ in city $j$ per unit of water allocated (US $\left.\$ / \mathrm{m}^{3}\right)$; $T_{i j}^{ \pm}$is water-allocation target for user $i$ in city $j\left(\mathrm{~m}^{3}\right)$, which is the first-stage decision variable; $p_{h}$ is related probability of available water level, with $p_{h}>0$ and $\sum p_{h}=1 ; q_{h}^{ \pm}$is the available water for allocation, which is presented in terms of random variable $\left(\mathrm{m}^{3}\right) ; A G$ is the ratio of water supply to the agricultural sector (\%); EC is ratio of water supply to the ecological sector (\%); $R E$ is the ratio of water supply to satisfy regional development $(\%) ; D e_{i j}^{-}$is the lower water demand of user $i$ in city $j\left(\mathrm{~m}^{3}\right) ; D e_{i j}^{+}$is the upper water demand of user $i$ in city $j$ $\left(\mathrm{m}^{3}\right) ; V C_{i j}^{ \pm}$is the cost of per unit water allocated $\left(\mathrm{US} \$ / \mathrm{m}^{3}\right) ; \alpha$ is the confidence level, and $\alpha \in(0,1) ; \lambda$ is the weight of goal programming, and $\lambda \in[0,1] ; \eta^{ \pm}$is the system's maximum loss under $\alpha$ level; $v_{h}^{ \pm}$is the positive auxiliary variable.

\subsection{Data Acquisition}

Table 1 presents the related economic data expressed as intervals or ranges of economic data (net benefits and penalties) when water is delivered and/or not delivered) as derived from 


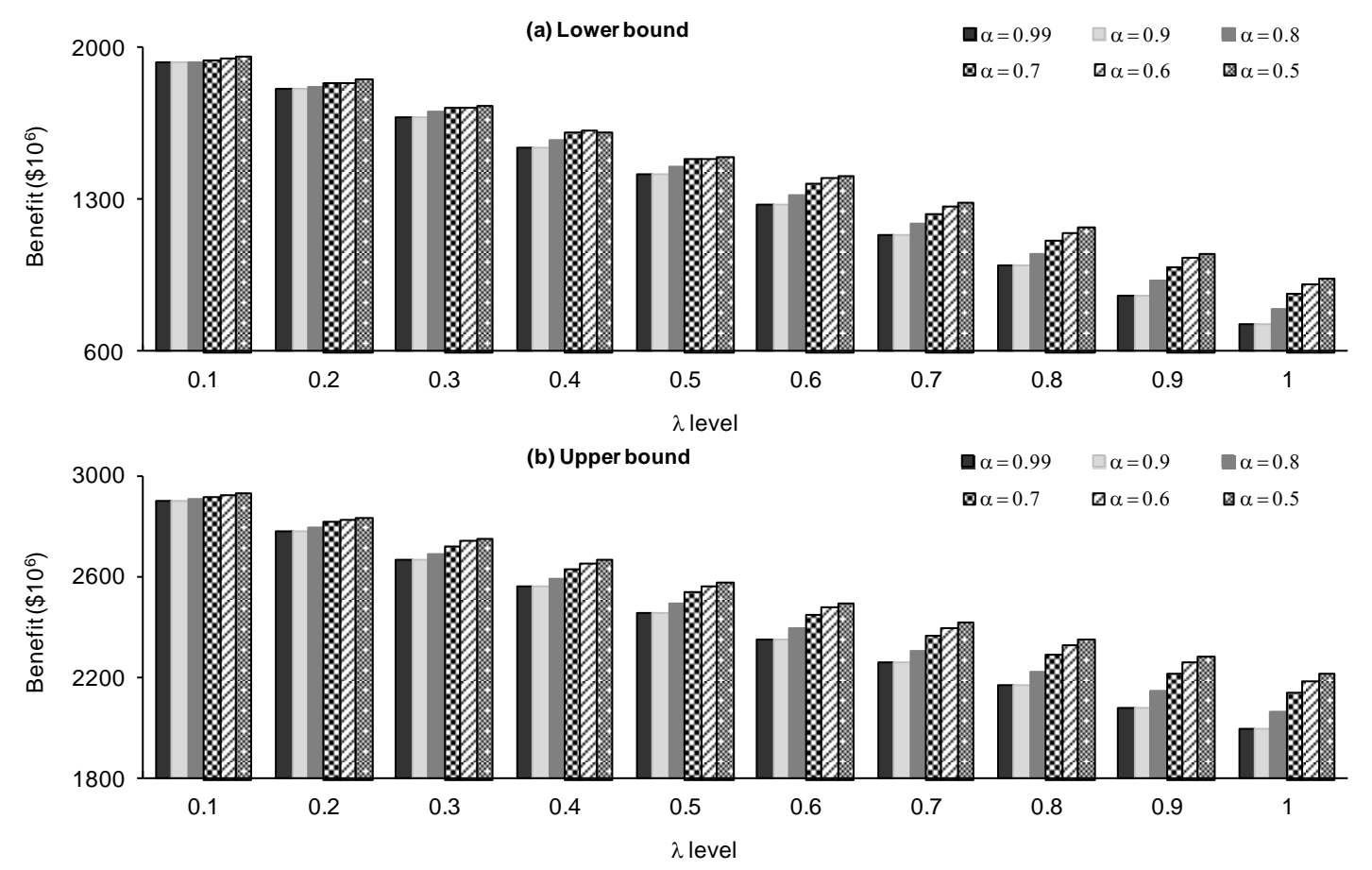

Figure 2. System benefits under different $\alpha$ and $\lambda$ levels.
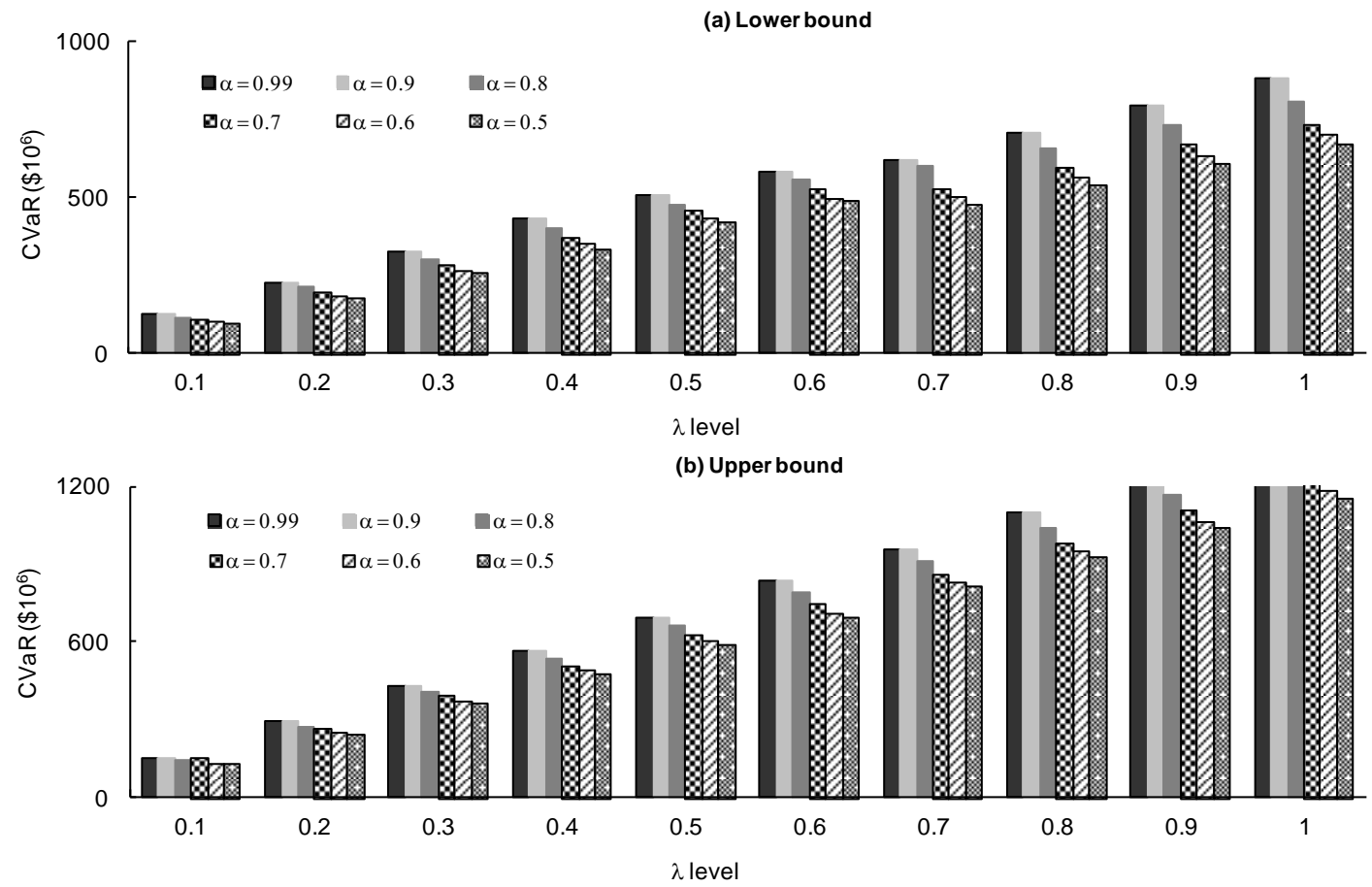

Figure 3. CVaR costs under different $\alpha$ and $\lambda$ levels.

statistical yearbooks of Xinjiang Uygur Autonomous Region in Uygur Autonomous Region 2005 2014. Various factors (e.g., product quality, market price, labor/energy fee) could affect the benefit from water allocation and cost for water delivery; water resource allocation also involves volumes of capital from multiple sources, leading to different interest rates. Penalties are associated with the acquisition of water from higher- priced alternatives and/or the negative consequences generated from the curbing of regional development plans. Table 2 lists the water demands from different users in the six cities. In the study area, agriculture is the largest consumer of water; due to the arid climate with low precipitation, all agricultural activities depend on irrigation with the river water being the most important source of such water. In the past decades, unreasona- 

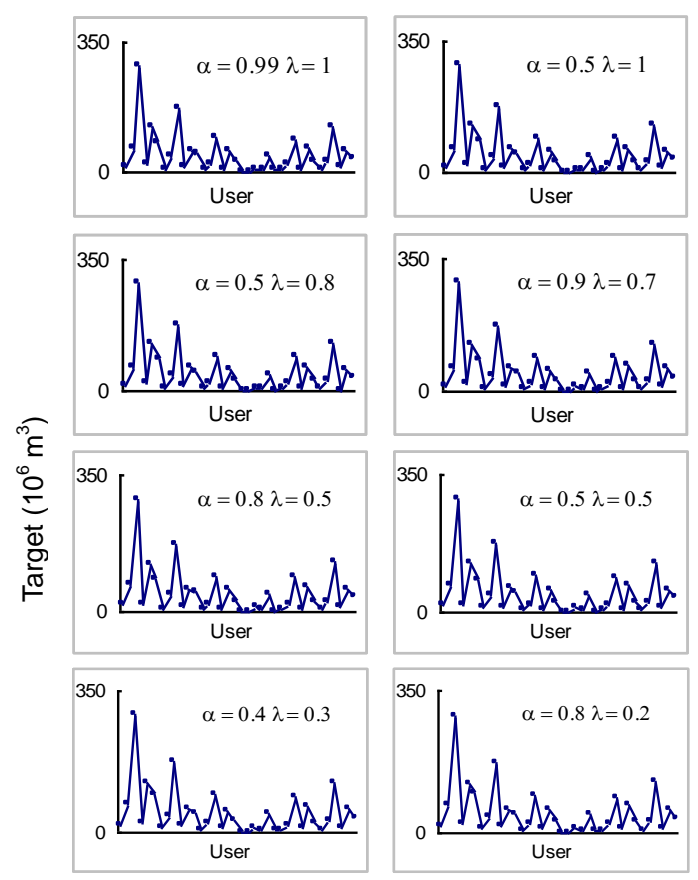

(a) Lower bound
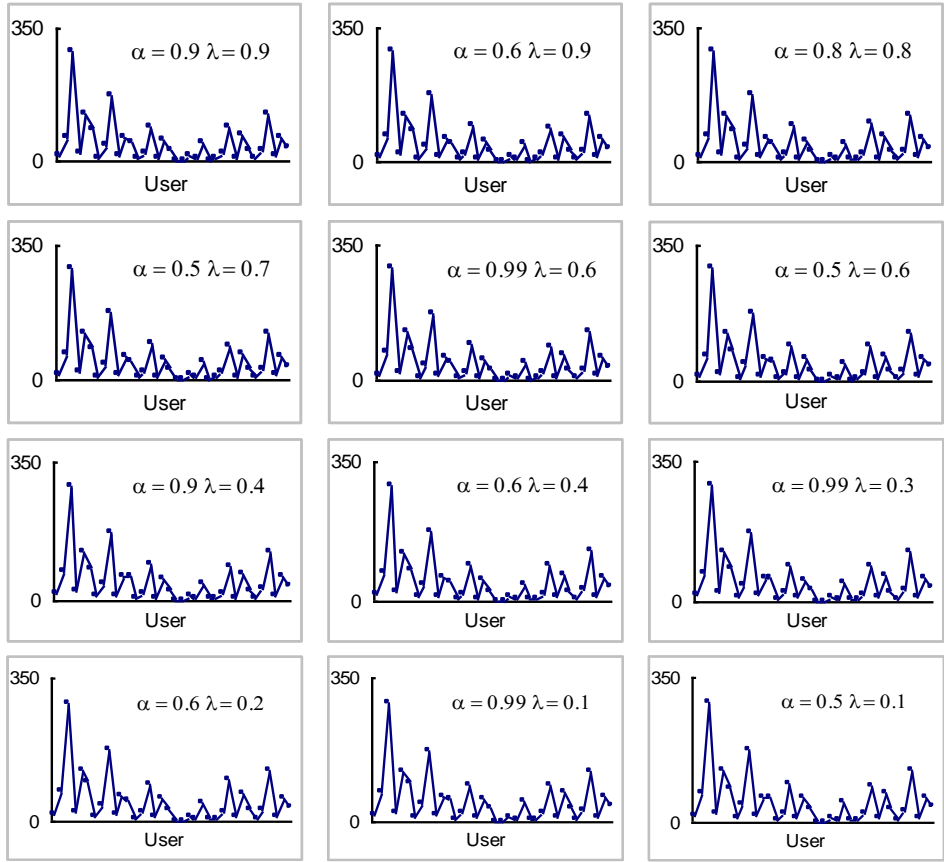

(b) Upper bound
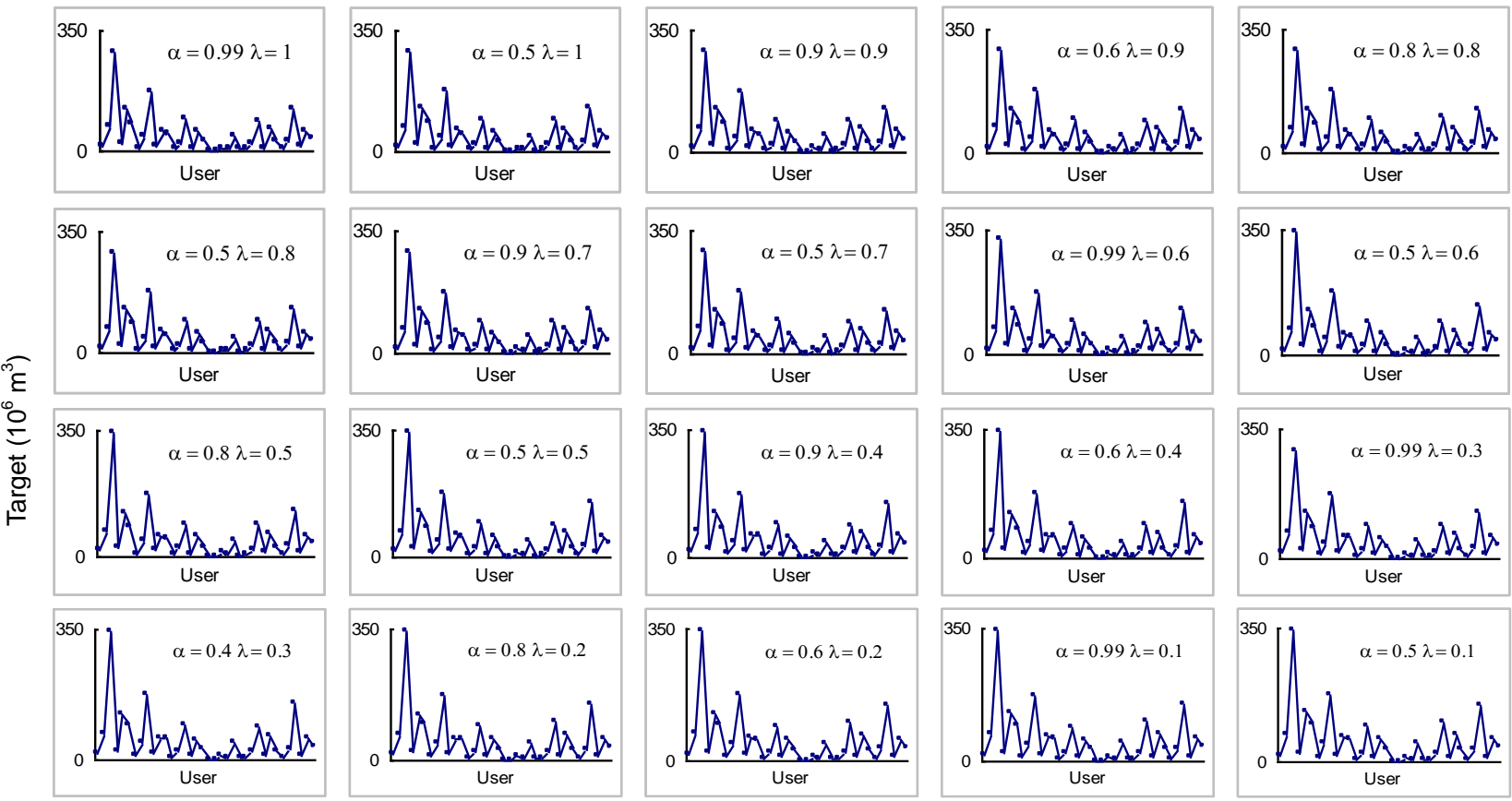

Figure 4. Optimized target for each user under different scenarios.

ble land and water resource utilization have resulted in spatiotemporal changes in the water distribution pattern of the watershed as well as the degradation of natural vegetation and the aggravation of desertification of its lower reach (Thevs et al., 2015). To guarantee the oasis ecosystem sustainability, the ecological water requirements of desert riparian vegetation in the inland river are considered in this study. Table 3 provides the varied river-flow levels, water availabilities for allocation, as well as the associated probabilities. The random inputs of stream flow are provided by statistical analysis of the simulation outcomes of the Nedbor-Afstromnings model; the interval values of water flow under different probability levels are calculated based on a Gamma distribution (i.e. the best fit for the stream flow). 


\section{Results and Discussion}

\subsection{System Benefit and CVaR Cost}

In this study, six values for $\alpha$ (from 0.5 to 0.99 ) and ten values for $\lambda$ (from 0.1 to 1 ) were utilized, such that sixty scenarios were examined based on different combinations of $\alpha$ and $\lambda$ levels; this could help to investigate the risks of violating the constraints and generate a range of decision alternatives under uncertainty. Figure 2 presents system benefits under the sixty scenarios in association with different $\alpha$ and $\lambda$ levels. For example, when the confidence level is $0.99(\alpha=0.99)$, system benefits would be $\$[1934.6,2896.8] \times 10^{6}$ under $\lambda=0.1$ and $\$[722.5$, 1993.0] $\times 10^{6}$ under $\lambda=1$, implying that a higher $\lambda$ value (corresponding to an increased risk-control level) results in a lower system benefit. By varying the $\lambda$ level, decision makers can acquire the compromise between expected system benefit and system-failure risk. When $\lambda=0.5$, system benefits would be $\$[1495.5,2578.1] \times 10^{6}(\alpha=0.5)$ and $\$[1415.3,2453.1] \times 10^{6}$ $(\alpha=0.99)$; a higher $\alpha$ value associated with a reduced violation risk (an increased reliability level) leads to a lower system benefit. Generally, both higher $\alpha$ and $\lambda$ levels can lead to a reduced system benefit; however, this reduction also corresponds to a lower risk level (i.e. increased system reliability). Figure 3 shows the CVaR costs under different $\alpha$ and $\lambda$ levels. The highest $\mathrm{CVaR}$ cost (i.e. $\$[882.3,1369.8] \times 10^{6}$ ) would be achieved when $\alpha=0.99$ and $\lambda=1$; the system would possess the lowest $\mathrm{CVaR}$ cost (i.e. $\$[97.9,127.9] \times 10^{6}$ ) when $\alpha=0.5$ and $\lambda$ $=0.1$. The lower-bound CVaR corresponds to the upper-bound system benefit $\left(f^{+}\right)$while the upper-bound CVaR is related to the lower-bound system benefit $\left(f^{-}\right)$. The results reveal that the CVaR cost would increase when $\alpha$ and $\lambda$ levels are raised; an increased $\mathrm{CVaR}$ cost corresponds to a raised system-reliability level (i.e. a reduced system-failure risk).

\subsection{Water Allocation and Uncertainty Analysis}

The optimized water-allocation targets (i.e. the first-stage decision variables) for the users could be obtained through solving model (10) under various $\alpha$ and $\lambda$ levels. Figure 4 presents the solution of optimized target for thirty-six users (i.e. municipal, industrial, agricultural, stockbreeding, forestry and ecology users in six cities) under twenty scenarios. Results indicate that different $\alpha$ and $\lambda$ levels (i.e. different risk levels) would result in varied water-allocation targets. For example, for ecology in Kuerle, the optimized lower- and upper-bound targets would be $80.7 \times 10^{6} \mathrm{~m}^{3}$ when $\alpha=0.99$ and $\lambda=1$; when $\alpha=0.8$ and $\lambda=0.2$, the lower- and upper-bound targets would increase to $96.9 \times 10^{6} \mathrm{~m}^{3}$. Figure 5 summarizes the total allocation targets for all users under the twenty scenarios. The lowerbound values of total allocation target would range from 1682.3 $\times 10^{6} \mathrm{~m}^{3}(\alpha=0.5$ and $\lambda=0.8)$ to $1762.5 \times 10^{6} \mathrm{~m}^{3}(\alpha=0.99$ and $\lambda=0.1)$; the minimum and maximum values for upper-bound targets would vary from $1702.1 \times 10^{6} \mathrm{~m}^{3}(\alpha=0.5$ and $\lambda=1)$ to $1893.4 \times 10^{6} \mathrm{~m}^{3}(\alpha=0.5$ and $\lambda=0.1)$. Generally, as $\alpha$ and $\lambda$ values increase, the allocation target would decrease, leading to a reduced water shortage. In such a case, the extreme risk could be lowered and the system feasibility be enhanced. On the contrary, lower $\alpha$ and $\lambda$ values would result in a higher po- ssibility of system loss in extreme conditions. Figure 6 provides the solutions of expected water allocations under twenty scenarios. For example, when $\alpha=0.99$ and $\lambda=1$, the expected water allocated to agriculture in Kuerle would be $288.8 \times 10^{6}$ $\mathrm{m}^{3}$; when $\alpha=0.5$ and $\lambda=0.1$, the expected water allocated to agriculture in Kuerle would be $[288.8,346.5] \times 10^{6} \mathrm{~m}^{3}$. Results show that decision makers' risk attitudes (corresponding to different $\alpha$ and $\lambda$ levels) have significant effect on water-allocation pattern.

Figure 7 presents the solutions of water-allocation plans for multiple users under nine scenarios. Each allocated water flow is the difference between the optimized target and the probabilistic shortage under a given river-flow condition with an associated probability level. For example, when $\alpha=0.99$ and $\lambda=1$, the optimized target for agriculture would be 776.4 $\times 10^{6} \mathrm{~m}^{3}$; when available flow level is low (probability = $15.2 \%$ ), the water actually allocated to agriculture would be $[459.2,577.4] \times 10^{6} \mathrm{~m}^{3}$; this means that the shortage for agriculture is $[199.0,317.2] \times 10^{6} \mathrm{~m}^{3}$ under the low flow. The solution implies that there would be no water shortage for agriculture if the water flow reaches medium-high. In comparison, when $\alpha=0.5$ and $\lambda=0.1$, the optimized allocation target for agriculture would be $[776.4,878.7] \times 10^{6} \mathrm{~m}^{3}$; the water allocated to this user would be $[511.4,613.7] \times 10^{6} \mathrm{~m}^{3}$ when the flow level is low. Figure 8 provides the solutions of water allocated to six cities under different flow levels. The results also indicate that water-allocation schemes would be different as $\alpha$ and $\lambda$ levels are varied; this reveals that both uncertainties (random water availability) and risk attitudes ( $\alpha$ and $\lambda$ levels) may impact water allocation schemes.

Figures 9 and 10 summarize the relationship between water demand and allocation for users and cities under two extreme scenarios. Solutions indicate that, when flow is low, the water allocated to all users would be $[983.6,1161.1] \times 10^{6} \mathrm{~m}^{3}$ under $\alpha=0.99$ and $\lambda=1$, and [983.6, 1160.4] $\times 10^{6} \mathrm{~m}^{3}$ under $\alpha$ $=0.5$ and $\lambda=0.1$; however, the total water demand is [1690.0, $1966.0] \times 10^{6} \mathrm{~m}^{3}$, indicating a period of serious shortage in water supply. In the situation of insufficient water supply, the allotment to ecological user would be first decreased but with the minimum promised target being guaranteed; water shortage would then be passed to the forest sector. Scarce water resources and growing water competition would both reduce water availability/supply for ecological and forest sectors. This is mainly because the ecology and forest uses correspond to lower benefits and penalties, compared with the other users. When

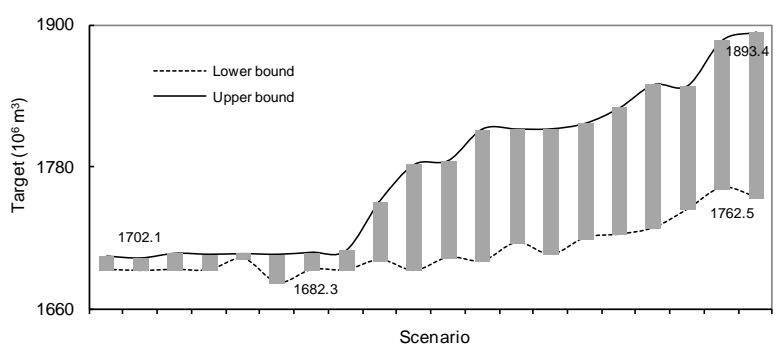

Figure 5. Total allocation targets under different scenarios. 

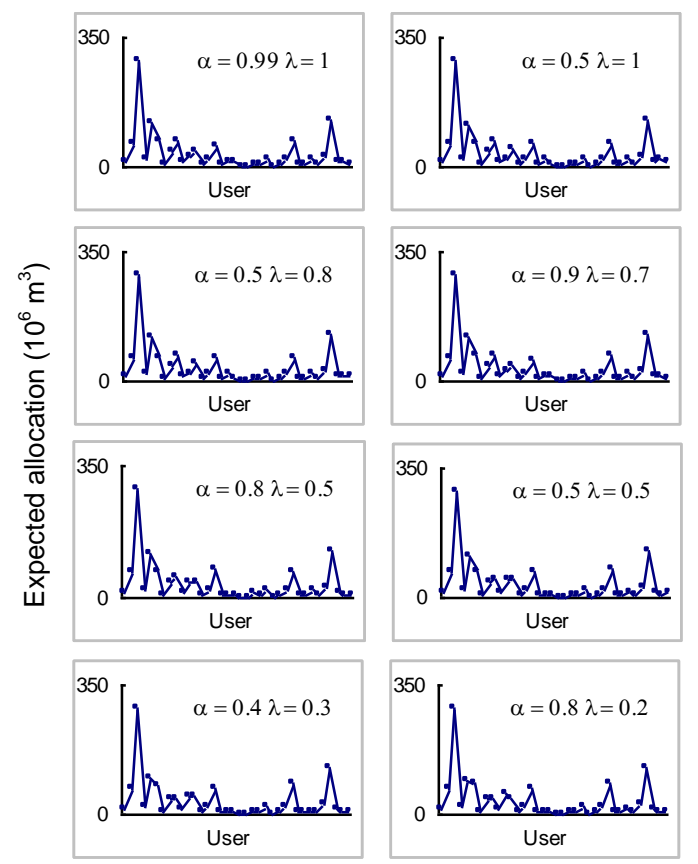

(a) Lower bound
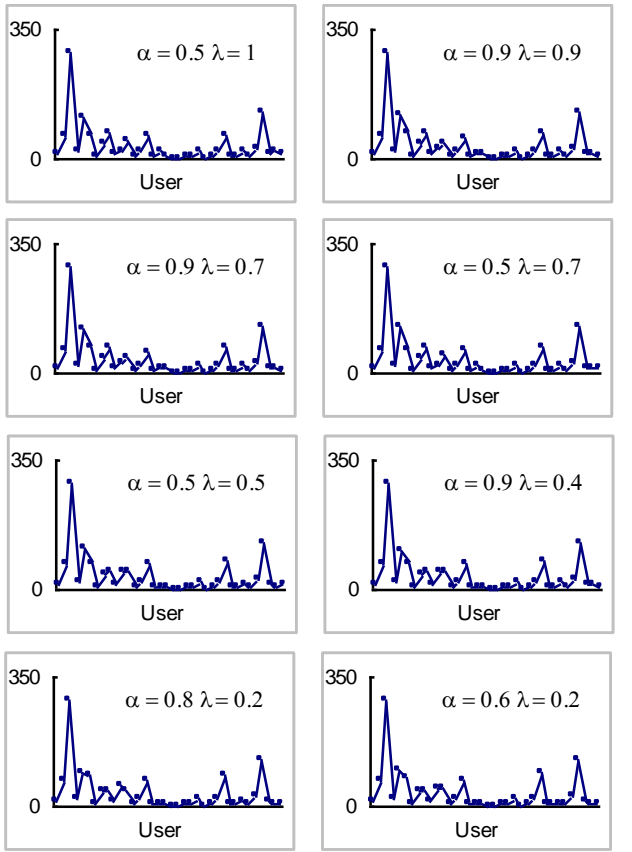

(b) Upper bound
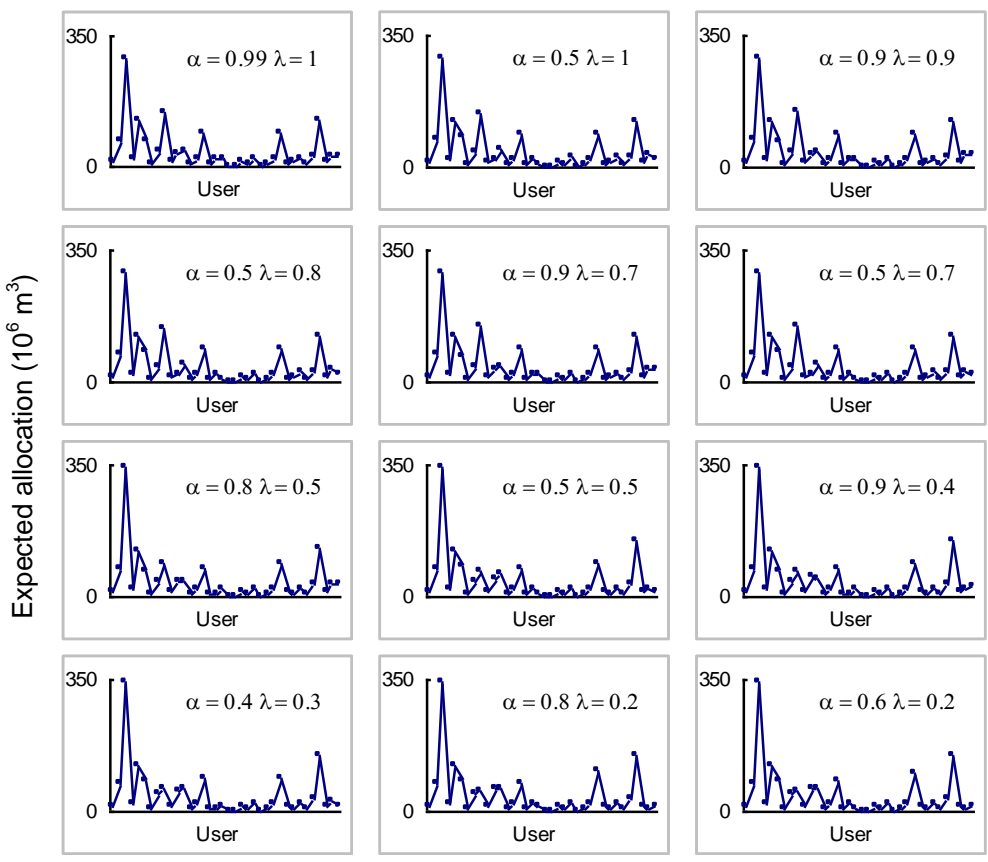
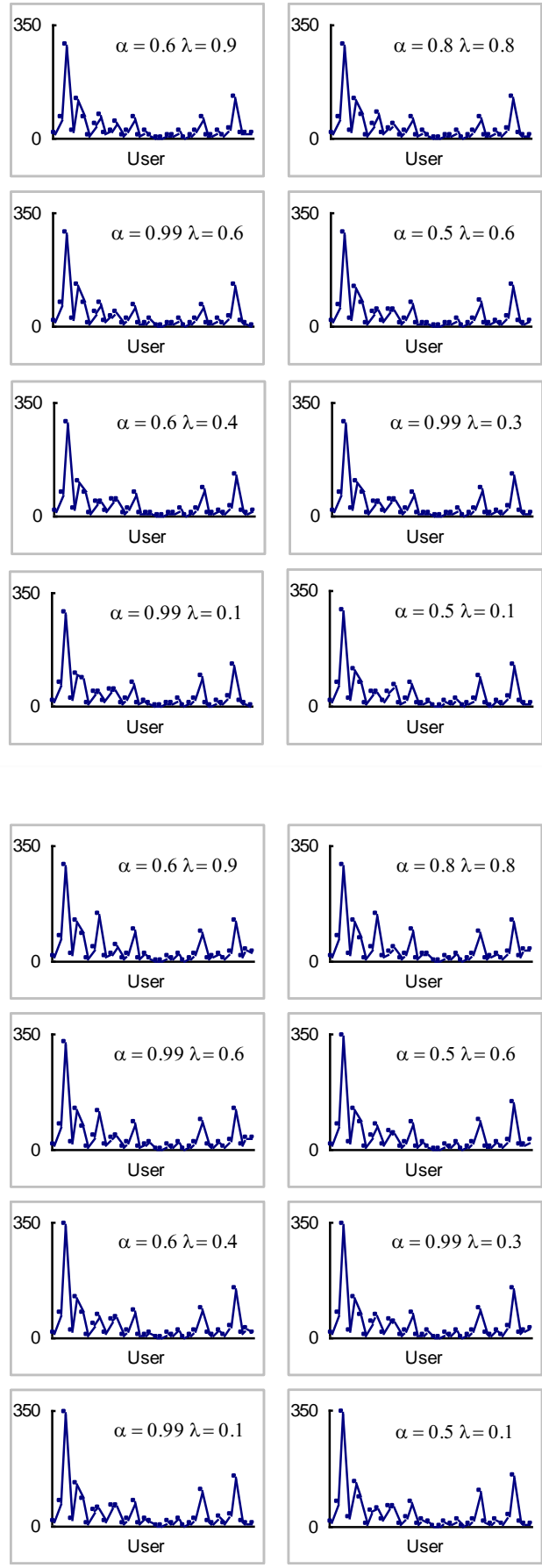

Figure 6. Expected water-allocation (to each user) under different scenarios.

merely limited water resources are available for multiple competing users, the competitiveness can strengthen the ecological water shortage and deteriorate regional eco-environment system (e.g., deforestation and desertification).

The results indicate that there would be no water shortage for municipal user under all flow levels. The municipal use should be of the highest priority since it brings the highest benefit when its water demand is satisfied; meanwhile, it is subject to the highest penalty if the promised water is not delivered. In future, restrictions for municipality water allocation may be introduced when flow is very low, which may be used to demonstrate the implied value of water by the losses that occur in the agricultural sector (the marginal value of crops foregone). For all cities, Kuerle is a major consumer, and its water consumption occupies approximately $35.1 \%$ of the total water uses. Among all users, the agricultural sector is the largest water con- 
(a) Lower bound
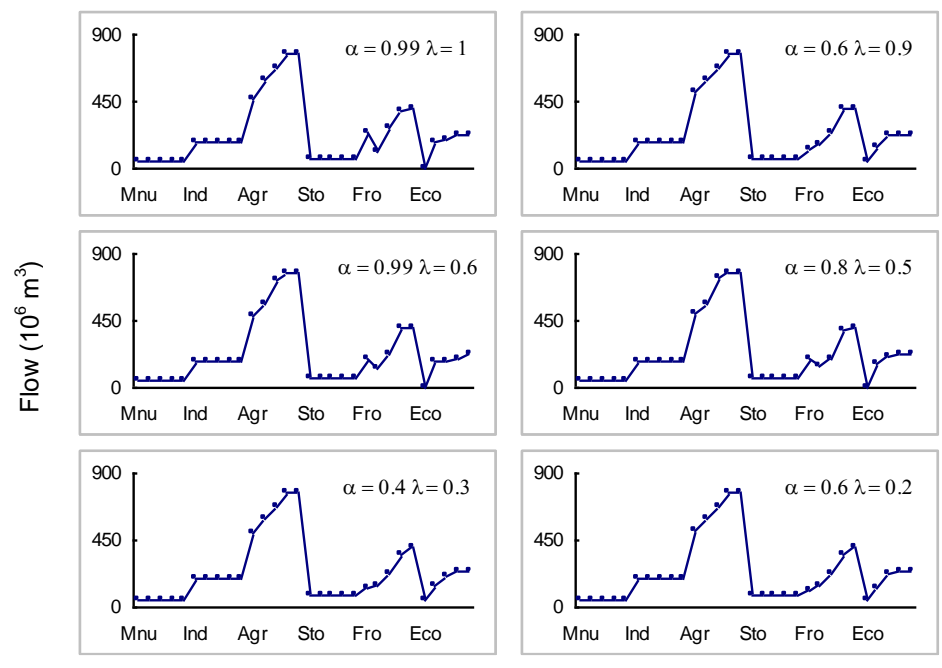

(b) Upper bound

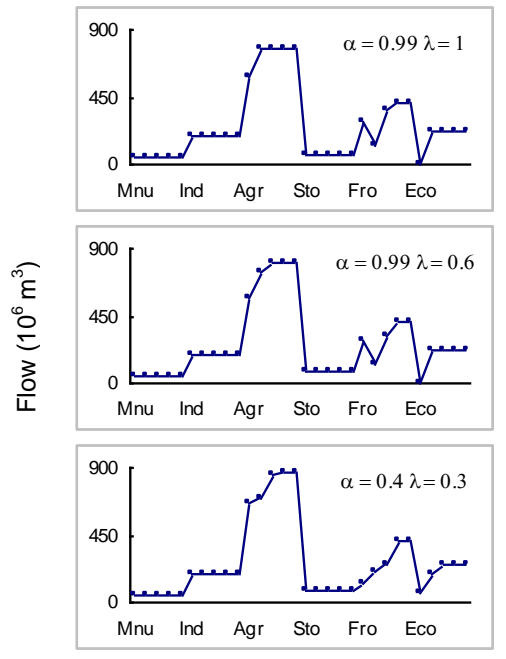

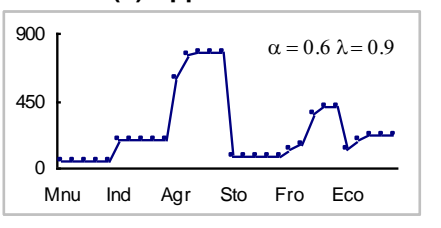
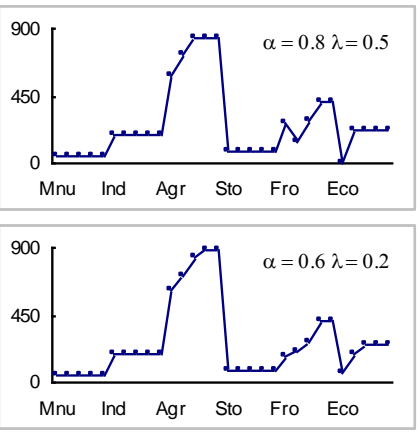
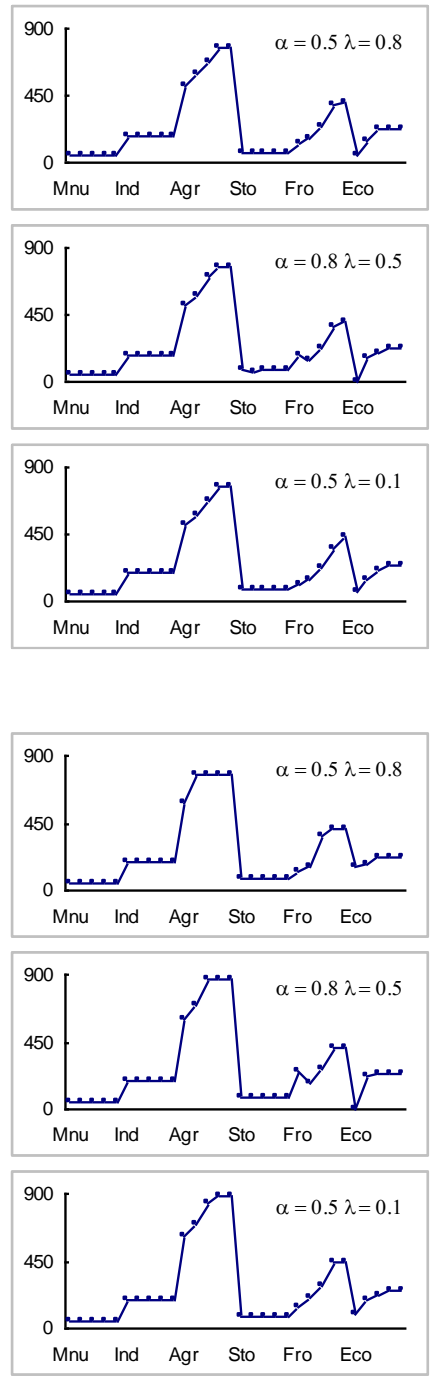

Figure 7. Water allocated to user under different flow levels (Symbols of "Mun, Ind, Agr, Sto, For and Eco" denote that "municipality, industry, agriculture, stockbreeding, forestry and ecology”, respectively).

sumer in the study watershed (accounting for approximately $46.7 \%$ of the total water demands). When the targeted water supply cannot be satisfied, the local farmers often obtain water through overexploiting groundwater; the largely uncontrolled groundwater use can produce far-reaching environmental and social problems (e.g., water table depletion, groundwater quality degradation, destruction of associated water ecosystem, proliferation of free-riding behaviors). This may further result in a number of negative impacts on regional sustainable development. Therefore, effective water management plays an important role in facilitating sustainable economic and eco-environmental development in the study region.

\subsection{Comparison to the Conventional TSP}

The problem under study can also be formulated into a two-stage interval-stochastic programming (TISP) model, without considering the $\mathrm{CVaR}$. This also implies that the decision makers would obtain the maximum system benefit without taking the risk of model's feasibility and reliability into consideration. Figures 11 and 12 compare the optimized targets and water allocations from TISP and ITRA (at $\alpha=0.99$ and $\lambda=1$ ), implying that the optimized targets and water-allocation patterns from TISP and ITRA would be different from each other. The total allocation targets for all users would be [1850.1, 1942.4] $\times 10^{6} \mathrm{~m}^{3}$ from TISP and $[1693.4,1703.7] \times 10^{6} \mathrm{~m}^{3}$ from ITRA; the expected allocations would be $[1274.7,1497.9] \times 10^{6} \mathrm{~m}^{3}$ from TISP and $[1267.8,1467.2] \times 10^{6} \mathrm{~m}^{3}$ from ITRA; the expected shortages would be $[352.2,667.7] \times 10^{6} \mathrm{~m}^{3}$ from TISP and $[226.2,435.9] \times 10^{6} \mathrm{~m}^{3}$ from ITRA. Solutions of the TISP also provide two extremes of the expected system benefit (i.e. $\$[2069.6,3029.7] \times 10^{6}$ ), which are both higher than those obtained through all cases of ITRA. This is because the objective of the TISP model (with risk neutral) to maximize the difference of the first-stage benefit and the second-stage random penalty, without considering the $\mathrm{CVaR}$ cost (i.e. cost for violation 
(a) Lower bound
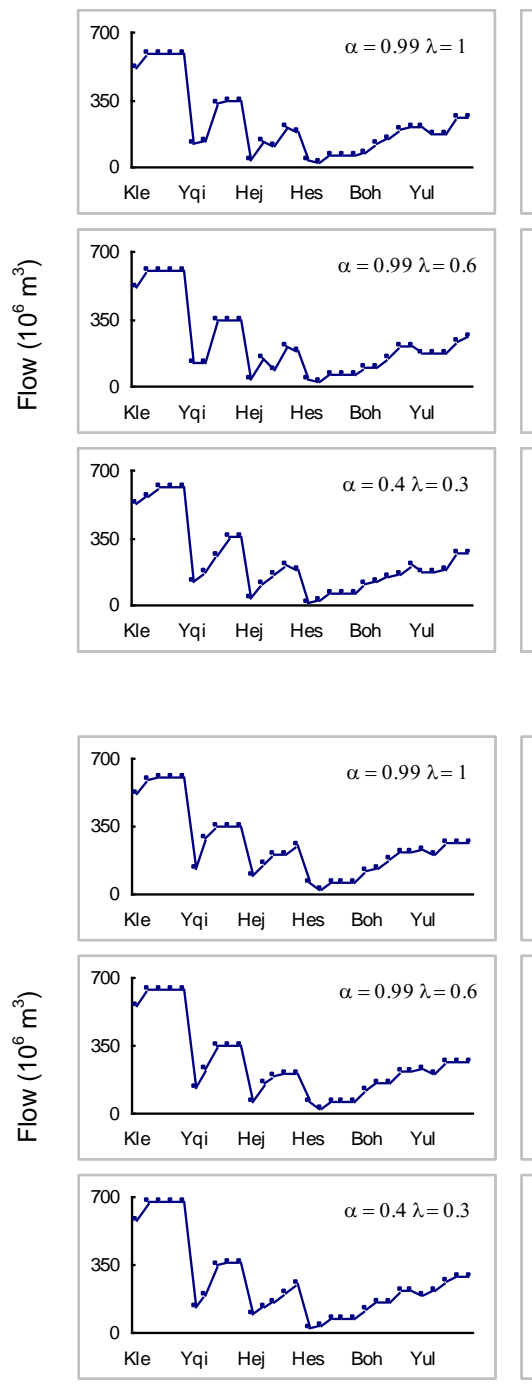
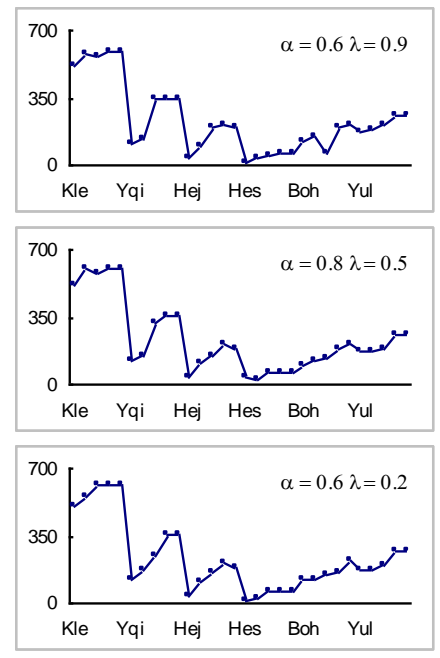

(b) Upper bound
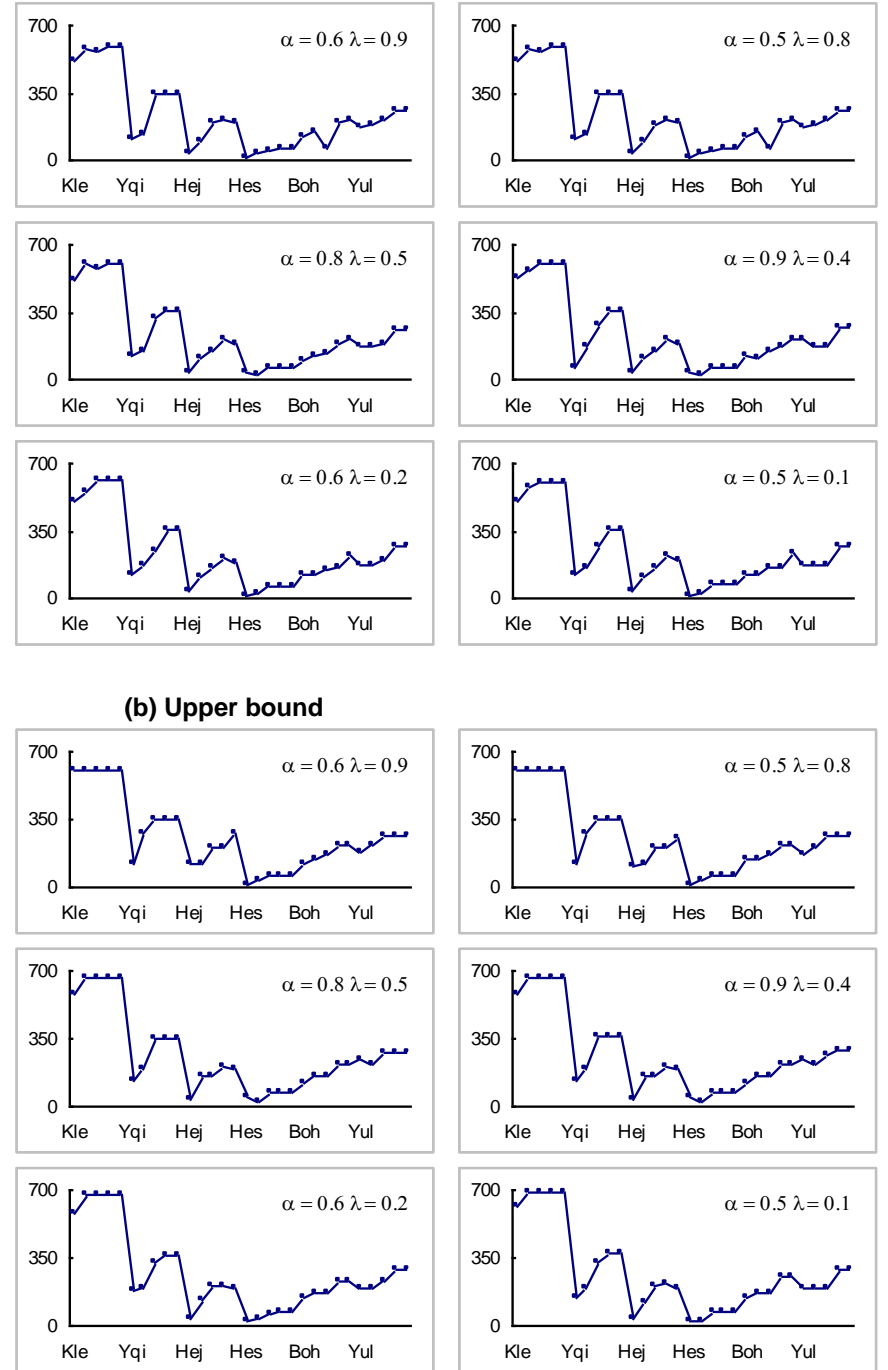

Figure 8. Water allocated to city under different flow levels (Symbols of "Kle, Yqi, Hej, Hes, Boh, and Yul" denote that "Kuerle, Yanqi, Hejing, Heshuo, Bohu, and Yulin", respectively).

risk). Generally, variations in water-allocation targets would correspond to different policies for water allocation under uncertainty. A higher target level from TISP would lead to a higher benefit; however, a higher risk of water shortage from the TISP would occur (and thus a higher penalty) when the promised water is not satisfied. Results from ITRA could reflect the decision maker's attitude toward risk aversion and generate potential options for decision making in association with different system-reliability levels. This demonstrates that, compared to the conventional TSP approach (with risk-neutral), ITRA (with risk-averse) that considers the effects of the variability of random outcomes (i.e. the random total cost) could provide more robust solution.

\section{Conclusions}

In this study, an interval-based two-stage risk analysis
(ITRA) method has been developed for planning water resource systems under uncertainty. ITRA is a hybrid for risk management and inexact optimization, where the concepts of intervalparameter and CVaR are incorporated within a two-stage stochastic programming (TSP) framework. It can tackle uncertainties presented as probability distributions and interval values. Risk-aversion measures are incorporated into the modeling formulation to reflect the preference of decision makers, such that the tradeoff between system economy and extreme expected loss are analyzed. Compared to the conventional TSP (with risk neutral), results from ITRA could reflect the decision maker's attitude toward risk aversion and generate potential options for decision making in association with different system-reliability levels. ITRA that considers the effects of the variability of random outcomes (i.e. the random total cost) could provide more robust solutions.

The ITRA method has been applied to a real case of the 


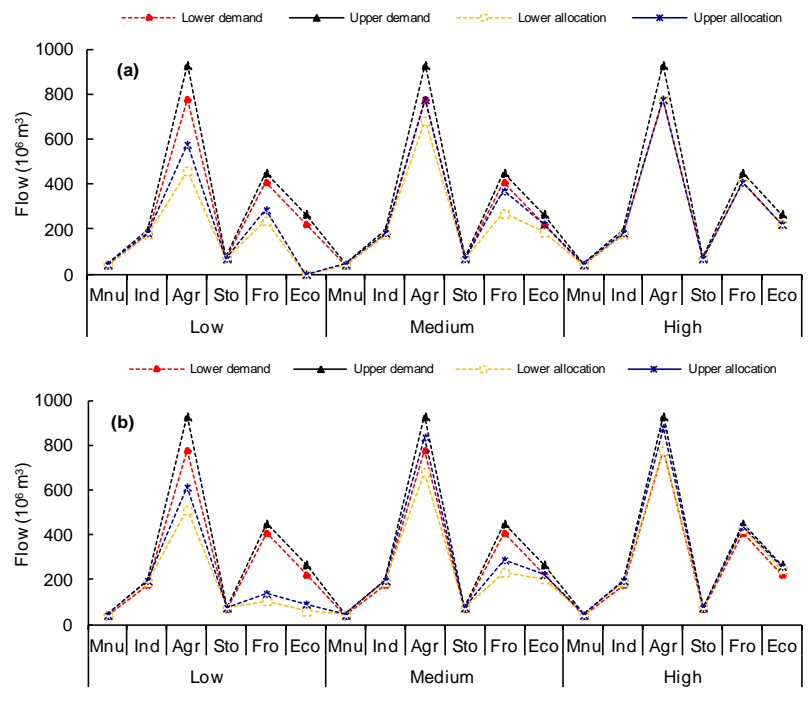

Figure 9. Relationship between allocation and demand for different users [(a) $\alpha=0.99$ and $\lambda=1$; (b) $\alpha=0.5$ and $\lambda=0.1$ ].

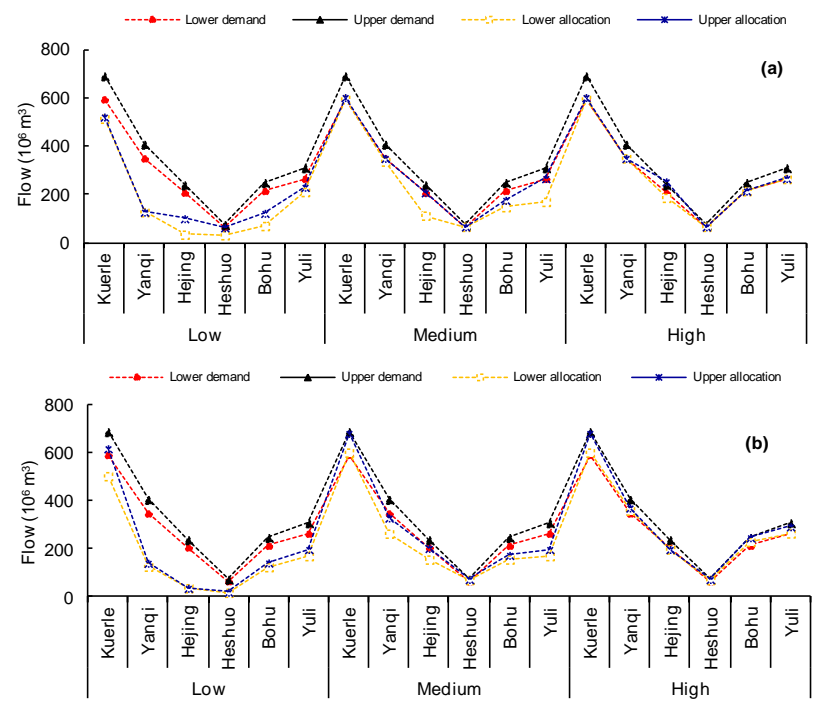

Figure 10. Relationship between allocation and demand for different cities [(a) $\alpha=0.99$ and $\lambda=1$; (b) $\alpha=0.5$ and $\lambda=0.1$.

Kaidu-kongque watershed, an extremely arid region in northwest China, for water resource management and planning. The ecosystem has decreased significantly in the watershed due to over-exploitation of water and land resources for agricultural and economic development. In this study, a number of risk measures are designed, such that 60 scenarios have been examined based on combinations of different $\alpha$ and $\lambda$ levels. Results obtained can help investigate the risks of violating the constraints and generate a range of decision alternatives under uncertainty. Results show that uncertainties and risk-attitudes have significant effects on water-allocation patterns (including targets and shortages) as well as system benefits (including the first-stage income and the second-stage penalty). Both higher $\alpha$ and $\lambda$ levels can lead to reduced system benefits; how- ever, this reduction also corresponds to increased system reliability. Results also disclose that, when limited water resources are available for multiple competing users in such an arid area, the competitiveness can increase both the ecological water shortages and serious eco-environmental problems (i.e., increased ecological sustainability concerns). For all cities, Kuerle is a major consumer and its water consumption occupies around $35.1 \%$ of the total water uses. Among all users, agricultural sector is the largest water consumer in this watershed (accounting for $46.7 \%$ of the total water allocation), mainly due to the extensive agriculture exploration and improper irrigation approaches. Model outputs link prescribed water-allocation targets in decision making with various scales of regionalization policies (due to the existence of uncertainties). The insights drawn from the system-oriented, forward-looking, and preventative study can eventually help decision makers and stakeholders gain a scientific understanding of the consequences of decisions relating to sustainable water-resource management and planning in a fast-growing, economic development, and extremely arid region.

Acknowledgements: This research was supported by the National Key Research Development Program of China (2016YFA0601502 and 2016YFC0502803), the National Natural Science Foundation for Distinguished Young Scholar (51225904), and the National Natural Science Foundation of China (51520105013).

\section{References}

Ahmadi, A., Moridi, A., and Han, D. (2015). Uncertainty assessment in environmental risk through Bayesian networks. J. Environ. Inf., 25(1), 46-59. https://doi.org/10.3808/jei.201500294

Andersson, F., Mausse, H., Rosen, D., and Uryasev, S. (2001). Credit risk optimization with conditional value-at-risk criterion. Math. Program., 89(2), 273-291. https://doi.org/10.1007/PL00011399

Birge, J.R., and Louveaux, F.V. (1997). Introduction to Stochastic Programming, Springer, New York.

Brandtner, M. (2013). Conditional value-at-risk, spectral risk measures and (non-) diversification in portfolio selection problems - A comparison with mean-variance analysis. J. Bank. Finance, 37(12), 5526-5537. https://doi.org/10.1016/j.jbankfin.2013.02.009

Cai, X.M., McKinney, D.C., and Lasdon, L.S. (2002). A framework for sustainability analysis in water resources management and application to the Syr Darya Basin. Water Resour. Res., 38(6), 1-14. https://doi.org/10.1029/2001WR000214

Chen, Y. N., Xu, C.C., Hao, X.M., Li, W H., Chen, Y.P., Zhu, C.G., and Ye, Z.X. (2009). Fifty-year climate change and its effect on annual runoff in the Tarim River Basin, China. Quatern. Int., 208 (1-2), 53-61. https://doi.org/10.1016/j.quaint.2008.11.011

Fan, Y.R, Huang, G.H., Huang, K., and Baetz, B.W. (2015). Planning water resources allocation under multiple uncertainties through a generalized fuzzy two-stage stochastic programming method. IEEE Trans. Fuzzy Syst., 23(5), 1488-1504. https://doi.org/10.1109/TFU ZZ.2014.2362550

Fan, Y.R., Huang, W.W., Huang, G.H., Li, Y.P., Huang, K. And Li,Z. (2016). Hydrologic risk analysis in the Yangtze River basin through coupling Gaussian mixtures into copulas. Adv. Water Resour., 88, 170-185. https://doi.org/10.1016/j.advwatres.2015.12.017

Harrison, K.W. (2007). Two-stage decision-making under uncertainty and stochasticity: Bayesian programming. Adv. Water Resour., 30(3), 641-664. https://doi.org/10.1016/j.advwatres.2006.03.006

Housh, M., Ostfeld, A., and Shamir, U. (2013). Limited multi-stage 

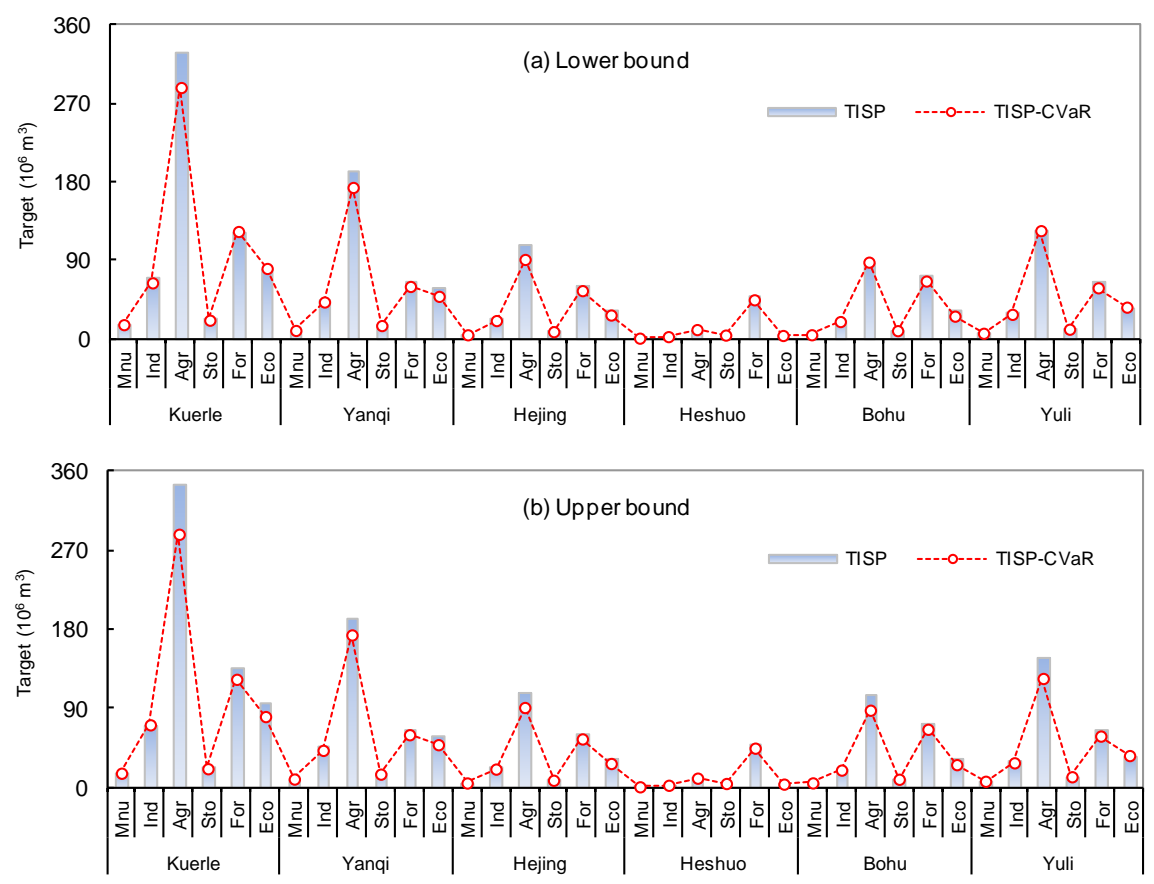

Figure 11. Water-allocation targets from TISP and ITRA (at $\alpha=0.99$ and $\lambda=1$ ).
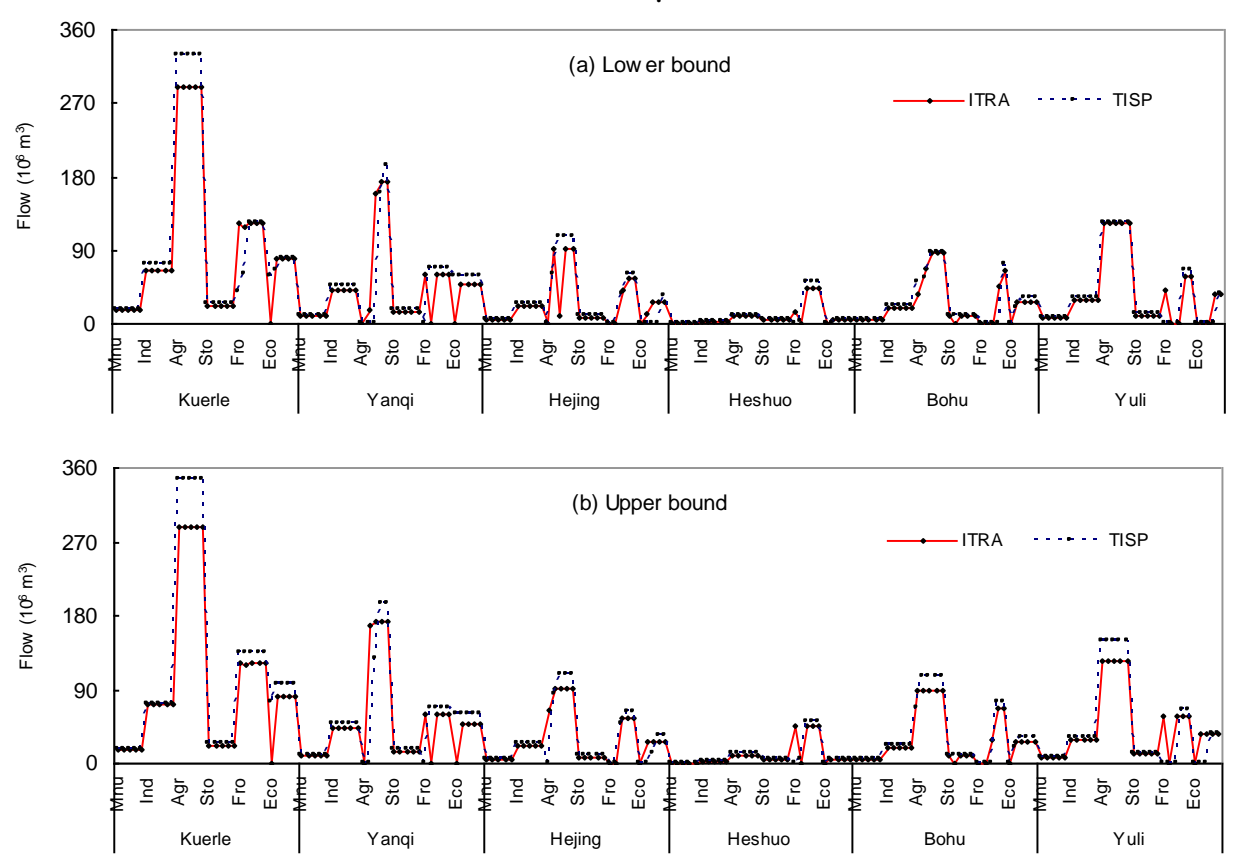

Figure 12. Water-allocation schemes from TISP and ITRA (at $\alpha=0.99$ and $\lambda=1$ ).

stochastic programming for managing water supply systems. Environ. Model. Software, 41, 53-64. https://doi.org/10.1016/j.envsoft. 2012.11.006

Huang, G.H., and Loucks, D.P. (2000). An inexact two-stage stochastic programming model for water resource management under uncertainty. Civ. Eng. Environ. Syst., 17(2), 95-118. https://doi.org/ 10.1080/02630250008970277

Huang, Y.P., Zheng, Q.P., and Wang, J.H. (2014). Two-stage stochas- tic unit commitment model including non-generation resource with conditional value-at-risk constraints. Electric Power Syst. Res., 116, 427-438. https://doi.org/10.1016/j.epsr.2014.07.010

Khor, C.S., Chachuat, B., and Shah, N. (2014). Fixed-flow rate total water network synthesis under uncertainty with risk management. J. Cleaner Prod., 77, 79-93. https://doi.org/10.1016/j.jclepro.2014. 01.023

Li, Z., Huang, G.H., Fan, Y.R., and Xu, J.L. (2015). Hydrologic risk 
analysis for nonstationary streamflow records under uncertainty. $J$. Environ. Inf., 26(1), 41-51.

Li, Y.P., Huang, G.H., Huang, Y.F., and Zhou, H.D. (2009). A multistage fuzzy-stochastic programming model for supporting sustainable water resources allocation and management. Environ. Model. \& Softw. 24, 786-797. http://dx.doi.org/10.1016/j.envsoft.2 008.11 .008

Li, Y.P., Huang, G.H., and Nie, S.L. (2010). Planning water resource management systems using a fuzzy-boundary interval-stochastic programming method. Adv. Water Res., 33, 1105-1117. https://doi. org/10.1016/j.advwatres.2010.06.015

Li, Y.P., Huang, G.H., and Nie, S.L. (2011) Optimization of regional economic and environmental systems under fuzzy and random uncertainties. J. Environ. Manage., 92(8), 2010-2020. https://doi.org/ 10.1016/j.jenvman.2011.03.022

Li, Y.P., Liu, J., and Huang, G.H. (2014). A hybrid fuzzy-stochastic programming method for water trading within an agricultural system. Agric. Syst., 123, 71-83. https://doi.org/10.1016/j.agsy.2013. 10.001

Marrero, G.A., Puch, L.A., and Ramos-Real, F.J. (2015). Mean-variance portfolio methods for energy policy risk management. Int Rev. Econ. Finance, 40, 246-264. https://doi.org/10.1016/j.iref. 2015.02.013

Nazemi, A., and Wheater, H.S. (2014). How can the uncertainty in the natural inflow regime propagate into the assessment of water resource systems? Adv. Water Res., 63, 131-142. https://doi.org/ 10.1016/j.advwatres.2013.11.009

Nematian, J. (2016). An extended two-stage stochastic programming approach for water resources management under uncertainty. $J$. Environ. Inf., 27(2), 72-84.

Piantadosi, J., Metcalfe, A.V., and Howlett, P.G. (2008). Stochastic dynamic programming (SDP) with a conditional value-at-risk (CVaR) criterion for management of storm-water. J. Hydrol., 348(3-4), 320-329. https://doi.org/10.1016/j.jhydrol.2007.10.007

Rahmani, M.A., and Zarghami, M. (2015). The use of statistical weather generator, hybrid data driven and system dynamics models for water resource management under climate change. J. Envi- ron. Inf., 25(1), 23-35. https://doi.org/10.3808/jei.201400285

Rockafellar, R.T., and Uryasev, S. (2002). Conditional value-at-risk for general loss distributions. J. Bank Finance, 26(7), 1443-1471. https://doi.org/10.1016/S0378-4266(02)00271-6

Shafiee-Jood, M., Cai, X., Chen, L., Liang, X.Z., and Kumar, P. (2014). Assessing the value of seasonal climate forecast information through an end-to-end forecasting framework: Application to U.S. 2012 drought in central Illinois. Water Resour. Res., 50, 6592-6609. https://doi.org/10.1002/2014WR015822

Soleimani, H., and Govindan, K. (2014). Reverse logistics network design and planning utilizing conditional value at risk. Eur. J. Oper. Res., 237(2), 487-497. https://doi.org/10.1016/j.ejor.2014.02.030

Thevs, N., Peng, H.Y., Rozi, A., Zerbe, S., and Abdusalih, N. (2015). Water allocation and water consumption of irrigated agriculture and natural vegetation in the Aksu-Tarim River Basin, Xinjiang, China. J. Arid Environ., 112, 87-97. https://doi.org/10.1016/j.jarid env.2014.05.028

Wang, C., Ao, Y.H., Wang, P.F., Hou, J., and Qian, J. (2010). Preparation, characterization, photocatalytic properties of titania hollow sphere doped with cerium. J. of Hazard. Mater., 178(1-3), 517-521. http://dx.doi.org/10.1016/j.jhazmat.2010.01.111

Wang, C., Lu, G.H., Wang, P.F., Wu, H., Qi, P.D., and Liang, Y. (2011). Assessment of Environmental Pollution of Taihu Lake by Combining Active Biomonitoring and Integrated Biomarker Response. Environ. Sci. Technol., 45(8), 3746-3752. http://dx.doi.org /10.1021/es1037047

Wang, P.F., Ao, Y.H., Wang, C., Hou, J., and Qian, J. (2012). A one-pot method for the preparation of graphene-Bi2MoO6 hybrid photocatalysts that are responsive to visible-light and have excellent photocatalytic activity in the degradation of organic pollutants. Carbon, 50(14), 5256-5264. http://dx.doi.org/10.1016/j.carbon.201 2.06.063

Zhuang, X.W., Li, Y.P., Huang, G.H., and Liu, J. (2016). Assessment of climate change impacts on watershed in cold-arid region: an integrated multi-GCM-based stochastic weather generator and stepwise cluster analysis method. Clim. Dyn., 47(1), 191-209. https:// doi.org/10.1007/s00382-015-2831-7 